\title{
Virus Mimetic Poly (I:C)-Primed Airway Exosome-like Particles Enter Brain and Induce Inflammatory Cytokines and Mitochondrial Reactive Oxygen Species in Microglia
}

\author{
Deimantė Kulakauskienè ${ }^{1,2}$, Deimantè Narauskaitė ${ }^{1}$, Dovydas Gečys ${ }^{1,3}{ }^{\mathbb{D}}$, Otilija Juknaitè ${ }^{1}$, \\ Lina Jankauskaitè ${ }^{1,4,5}$, Aistè Masaityte ${ }^{6}$, Jurgita Šventoraitienè ${ }^{6}$, Hermanas Inokaitis ${ }^{6}$, Zoja Miknienè ${ }^{7}$, \\ Ilona Sadauskienè ${ }^{8}{ }^{(0)}$, Giedrius Steponaitis ${ }^{9}{ }^{(\mathbb{C}}$, Zbigniev Balion ${ }^{1,10}$, Ramunè Morkūnienè ${ }^{2}$, Neringa Paužienè ${ }^{6}$, \\ Dainius Haroldas Pauža ${ }^{6}$ and Aistè Jekabsone ${ }^{1,11, * \mathbb{C}}$
}

1 Institute of Pharmaceutical Technologies, Faculty of Pharmacy, Lithuanian University of Health Sciences, LT-50162 Kaunas, Lithuania; deimante.kulakauskiene@lsmu.lt (D.K.); deimante.narauskaite@lsmu.lt (D.N.); dovydas.gecys@lsmuni.lt (D.G.); otilija.juknaite97@gmail.com (O.J.); lina.jankauskaite@lsmuni.lt (L.J.); zbigniev.balion@lsmuni.lt (Z.B.)

2 Department of Drug Chemistry, Faculty of Pharmacy, Lithuanian University of Health Sciences, LT-50162 Kaunas, Lithuania; ramune.morkuniene@lsmuni.lt

check for

updates

Citation: Kulakauskienè, D.; Narauskaitè, D.; Gečys, D.; Juknaitè, O.; Jankauskaitè, L.; Masaitytè, A.; Šventoraitienè, J.; Inokaitis, H.; Miknienė, Z.; Sadauskienè, I.; et al. Virus Mimetic Poly (I:C)-Primed Airway Exosome-like Particles Enter Brain and Induce Inflammatory Cytokines and Mitochondrial Reactive Oxygen Species in Microglia Biology 2021, 10, 1359. https:// doi.org/10.3390/biology10121359

Academic Editors: Guoku Hu, Simone Tambaro, Natalia Osna and Raghubendra S. Dagur

Received: 11 November 2021 Accepted: 16 December 2021 Published: 20 December 2021

Publisher's Note: MDPI stays neutral with regard to jurisdictional claims in published maps and institutional affiliations.

Copyright: (c) 2021 by the authors. Licensee MDPI, Basel, Switzerland. This article is an open access article distributed under the terms and conditions of the Creative Commons Attribution (CC BY) license (https:// creativecommons.org/licenses/by/ $4.0 /)$.
3 Laboratory of Molecular Cardiology, Institute of Cardiology, Lithuanian University of Health Sciences, LT-50162 Kaunas, Lithuania

4 Institute of Physiology and Pharmacology, Faculty of Medicine, Lithuanian University of Health Sciences, LT-50162 Kaunas, Lithuania

5 Department of Pediatrics, Faculty of Medicine, Lithuanian University of Health Sciences, LT-50161 Kaunas, Lithuania

6 Institute of Anatomy, Faculty of Medicine, Lithuanian University of Health Sciences, LT-44307 Kaunas, Lithuania; a.masaityte@gmail.com (A.M.); jurgita.sventoraitiene@lsmuni.lt (J.Š.);

hermanas.inokaitis@1smuni.lt (H.I.); neringa.pauziene@lsmuni.lt (N.P.); dainius.pauza@lsmuni.lt (D.H.P.)

7 Large Animal Clinic, Faculty of Veterinary Medicine, Lithuanian University of Health Sciences, LT-47181 Kaunas, Lithuania; zoja.mikniene@1smuni.lt

8 Laboratory of Molecular Neurobiology, Neuroscience Institute, Lithuanian University of Health Sciences, LT-50162 Kaunas, Lithuania; ilona.sadauskiene@1smuni.lt

9 Laboratory of Molecular Neurooncology, Neuroscience Institute, Lithuanian University of Health Sciences, LT-50162 Kaunas, Lithuania; giedrius.steponaitis@1smuni.lt

10 Laboratory of Biochemistry, Neuroscience Institute, Lithuanian University of Health Sciences, LT-50162 Kaunas, Lithuania

11 Laboratory of Preclinical Drug Investigation, Institute of Cardiology, Lithuanian University of Health Sciences, LT-50162 Kaunas, Lithuania

* Correspondence: aiste.jekabsone@lsmuni.lt; Tel.: +370-675-94455

Simple Summary: Upper respiratory tract viral infections are among the most common diseases. The blood-brain barrier protects the brain from direct invasion of pathogens. However, the cells share their content with other cells in small nanovesicles called exosomes that can travel long distances and cross biological barriers. Therefore, virus-infected cell extracellular vesicles (EVs) might transmit inflammatory signals or even viral particles to other cells. If they would carry such signals or particles to the central nervous system, it might cause neuroinflammation. However, the migration and impact of virus-primed airway cell EVs on the brain have not been studied yet. Therefore, the study aimed to track airway EVs from the respiratory tract to the brain and determine how infection-primed particles affect microglia - the cells responsible for immune response in the brain. The study revealed that airway cell EVs enter the brain within an hour and gather in microglia. Interestingly, many airway EVs were found in the hippocampus, the region most affected by Alzheimer's disease. Moreover, EVs from virus-infected airway cells stimulated reactive oxygen species in microglia and induced other inflammation mediators in the brain. Thus, airway cells indeed might communicate inflammatory information to the brain during viral infection.

Abstract: Viral infections induce extracellular vesicles (EVs) containing viral material and inflammatory factors. Exosomes can easily cross the blood-brain barrier during respiratory tract infection 
and transmit the inflammatory signal to the brain; however, such a hypothesis has no experimental evidence. The study investigated whether exosome-like vesicles (ELVs) from virus mimetic poly (I:C)-primed airway cells enter the brain and interact with brain immune cells microglia. Airway cells were isolated from Wistar rats and BALB/c mice; microglial cell cultures-from Wistar rats. ELVs from poly (I:C)-stimulated airway cell culture medium were isolated by precipitation, visualised by transmission electron microscopy, and evaluated by nanoparticle analyser; exosomal markers CD81 and CD9 were determined by ELISA. For in vitro and in vivo tracking, particles were loaded with Alexa Fluor 555-labelled RNA. Intracellular reactive oxygen species (ROS) were evaluated by DCFDA fluorescence and mitochondrial superoxide-by MitoSOX. ELVs from poly (I:C)-primed airway cells entered the brain within an hour after intranasal introduction, were internalised by microglia and induced intracellular and intramitochondrial ROS production. There was no ROS increase in microglial cells was after treatment with ELVs from airway cells untreated with poly (I:C). In addition, poly (I:C)-primed airway cells induced inflammatory cytokine expression in the brain. The data indicate that ELVs secreted by virus-primed airway cells might enter the brain, cause the activation of microglial cells and neuroinflammation.

Keywords: airway cell exosomes; viral infection; microglia; mitochondria; reactive oxygen species

\section{Introduction}

The upper respiratory tract is considered a gateway for viruses to enter the human body. Approximately $90 \%$ of the upper airway tract infections are caused by viruses [1], and over 200 different viruses have been isolated from the human upper respiratory tract [2]. Generally, respiratory viruses, such as rhinoviruses, influenza, adenoviruses, enteroviruses, does not spread to the distant tissues; however, accumulating evidence shows that viral material carried by extracellular vesicles (EVs) originating from infected cells might induce cellular alterations outside of the respiratory tract [3-5]. The blood-brain barrier protects the brain from direct invasion of pathogens. However, a class of EVs called exosomes can effectively cross the blood-brain barrier by adsorptive transcytosis, receptor-mediated and other suggested pathways and carry endogenous material to the brain from the peripheral circulatory system [6-8]. Exosomes are 30-150 nm diameter EVs formed by endosomal maturation pathways and essential for intercellular communication [8,9]. They are secreted by almost every cell type and present in various body fluids, including urine, blood, breast milk, and saliva [10]. Exosomes contain a variety of bioactive molecules such as proteins, lipids and several RNA species [11]. Studies have shown that exosomal cargo depends on the physiological state of the parental cell $[3,12,13]$. It was observed that exosome content alternates in response to viral infection and that exosomes isolated from infected cells can activate innate immune response [3]. Several studies have shown that viral material transported by EVs can induce immune response [14], viral replication [15], cell apoptosis, cytokine release suppression [16,17], as well as contribute to NLRP3 inflammasome and IL-1 $\beta$ production [18].

One of the most plausible exosome recipients in the brain are microglial cells. Microglia and non-parenchymal macrophages in the brain are mononuclear phagocytes that are essential in brain homeostasis. Microglia constitute $5-10 \%$ of total brain cells and are the only true CNS parenchymal macrophages interacting with neurons, astrocytes and oligodendrocytes $[19,20]$. Microglia are involved in synaptic plasticity by synaptic pruning in the developing and adult brain; they also phagocytose dying, dead, and sometimes healthy cells [21-23]. Additionally, microglia respond to an infection or brain damage by transforming into an active inflammatory phenotype and protecting the brain from pathogens. However, prolonged microglial activation might lead to neurodegenerative disease development [24]. Recent evidence indicates that peripheral infections can stimulate an immune response in the brain, causing irreversible genetic and epigenetic changes in brain immune cells leading to the formation of immune memory [25]. Antiviral immune response and 
immune memory formation are related to rearrangements in mitochondrial network and dynamics and involve reactive oxygen species (ROS) signalling [26]. Exosomes might carry viral particles and/or inflammatory molecules. One might speculate that exosomes produced during frequent recurrent viral respiratory infections might cause microglia activation and maintenance of immune reactivity in the brain. However, such a hypothesis has no experimental evidence yet. This study investigates whether exosomes from cultured airway epithelial cells and fibroblasts under simulated infection-treatment with virus mimetic Toll-like receptor-3 agonist poly (I:C) — can enter the brain after intranasal delivery and how they interact with brain immune cells microglia.

\section{Materials and Methods}

\subsection{Experimental Design}

The experimental design of the study is presented in Figure 1. First of all, airway cells were isolated from laboratory rodent lungs, cultivated and primed with poly (I:C). Then, ELVs were isolated, characterised and prepared for in vivo intranasal and in vitro cell culture introduction. In parallel, primary microglial culture was prepared. Next, the poly (I:C)-treated and untreated airway cell ELVs were introduced to cultivated microglia, and the cultures were monitored for particle internalisation and intracellular plus intramitochondrial ROS production. In addition, stained airway cell ELVs were intranasally introduced to laboratory mice, and particle localisation in immunostained microglial cells in the brain cryosections was monitored after 1,2,3, and $5 \mathrm{~h}$. Finally, poly (I:C)-primed airway ELVs-treated brains and microglial cultures were evaluated for inflammatory cytokine expression by qRT-PCR.

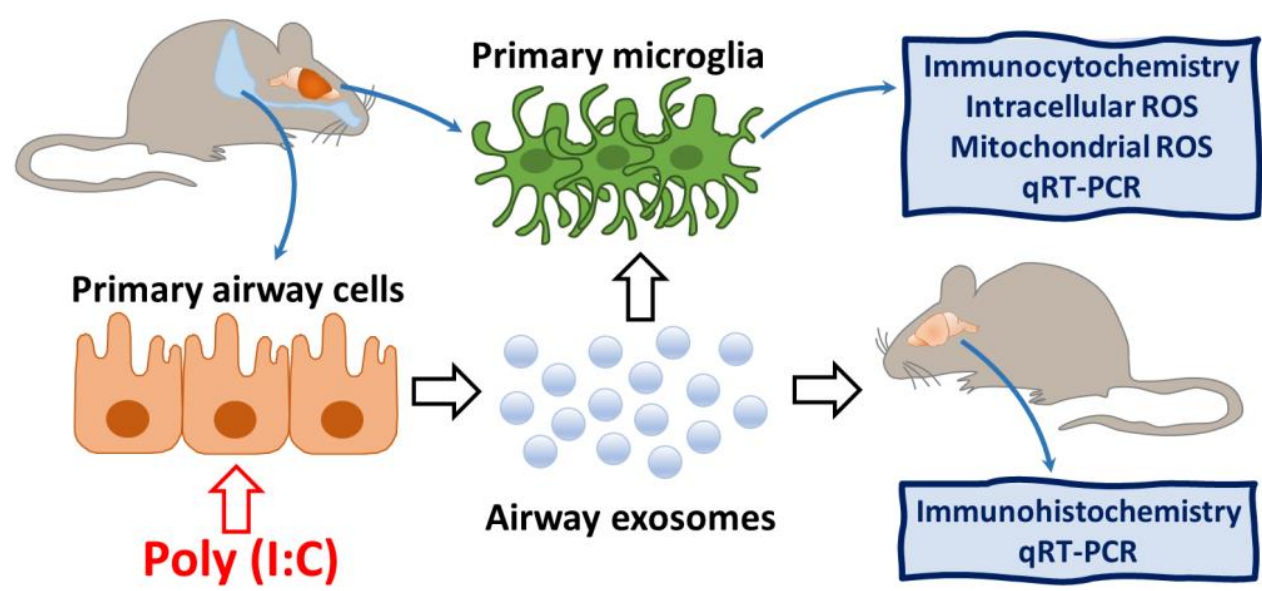

Figure 1. The experimental design of the study. Primary airway cells of rodent origin were treated with poly (I:C), and their ELVs were applied on microglial cell cultures and intranasally to mice. Microglial cells in vitro and in vivo were investigated for particle internalisation, and cultured microglia were analysed for intracellular and intramitochondrial ROS production.

\subsection{Primary Culture of Airway Cells}

Primary airway cells were prepared from 6-7-day-old Wistar rats for in vitro studies, and primary mouse airway cells for in vivo studies were made from 9-11 weeks old $\mathrm{Balb} / \mathrm{c}$ mice. All experimental procedures were performed according to the Republic of Lithuania Law on the Care, Keeping and Use of Animals. The rodents were maintained and handled at the Lithuanian University of Health Sciences animal house in agreement with the ARRIVE guidelines.

For isolation of airway cells, the animals were sacrificed by cervical dislocation. The trachea and lungs were exposed and separated from the thorax, followed by removal of the heart, trachea and large bronchi. The remaining lung tissue was rinsed twice with PBS, transferred to DMEM, minced with sharp scissors and digested in $1 \%$ trypsin in DMEM solution for up to $30 \mathrm{~min}$ at $37^{\circ} \mathrm{C}$ with gentle agitation. The digestion process 
was inactivated with the DMEM and 10\% FBS. The preparation was filtered through the $70-\mu \mathrm{m}$ cell strainer and centrifuged at $400 \times g$ for $10 \mathrm{~min}$ at $4{ }^{\circ} \mathrm{C}$. The cells in the pellet were suspended in a growth medium (DMEM with GlutaMAX ${ }^{\mathrm{TM}}, 25 \mathrm{mM}$ HEPES, $10 \% \mathrm{FBS}$ and $1 \%$, or 10,000 IU/mL, penicillin-streptomycin solution) and seeded in a T-75 flask. After $24 \mathrm{~h}$, the medium was removed, centrifuged again and the cells in the pellet were grown in a T-75 flask for 6-9 d until used for further experiments. According to morphological evaluation under a brightfield microscope, the cultures comprised of fibroblasts and epithelial cells at an approximate ratio of 1:1 (Figure A1).

\subsection{Cultures of Primary Mixed Glia and Pure Microglia}

Mixed glial and pure microglial cultures were prepared from 6-7-day-old Wistar rat pups, as described in [27], with minor modifications. All animal care and procedures were performed according to the Republic of Lithuania Law on the Care, Keeping and Use of Animals following ARRIVE guidelines. Briefly, after decapitation, cerebral cortices were separated from the remaining parts of the brain and placed in Petri dishes containing PBS, glucose $(13 \mathrm{mM})$, and penicillin-streptomycin solution $(10,000 \mathrm{IU} / \mathrm{mL}-10,000 \mu \mathrm{g} / \mathrm{mL})$. After removing the meninges, the cortical tissues were minced and transferred to the centrifugal tube with preheated $\left(37^{\circ} \mathrm{C}\right)$ Versene $\left(\right.$ Gibco $^{\mathrm{TM}}$, Thermo Fisher Scientific, Bleiswijk, The Netherlands, 1:50,000) solution and incubated for $10 \mathrm{~min}$ in $37^{\circ} \mathrm{C}$ with gentle agitation. After incubation, the solution was triturated with Pasteur pipettes and centrifuged at $290 \times g$ at room temperature. The pellet was resuspended in DMEM with GlutaMAX ${ }^{\mathrm{TM}}$, (Thermo Fisher Scientific, Bleiswijk, The Netherlands) and 10\% FBS, passed through 40- $\mu \mathrm{m}$ mesh, transferred to poly-L-lysine coated T-75 flasks and cultivated for $13 \mathrm{~d}$ replacing growth medium every 5 th $\mathrm{d}$. Microglial cells were detached by gently shaking the flask for $5 \mathrm{~min}$ on an orbital shaker, isolated by centrifugation at $290 \times g$ for $5 \mathrm{~min}$ and grown in T-75 flasks in the same growth medium.

\subsection{Isolation of ELVS}

Rat and mouse airway cells were cultured in T-75 flasks until reaching $70-80 \%$ confluency. The growth medium was replaced with DMEM without FBS to avoid contamination with EVs that are present in the serum. The cells were treated with $1 \mu \mathrm{g} / \mathrm{mL}$ poly (I:C) for $1 \mathrm{~h}$, washed with a serum-free medium to remove any exosomes and poly I:C, and then further incubated for $24 \mathrm{~h}$ in a serum-free medium without poly (I:C). After collection, the cell-conditioned medium was passed through $0.22 \mu \mathrm{m}$ PVDF filters. ELVs were isolated using Total Exosome Isolation Reagent (Invitrogen) according to the manufacturer's manual. Briefly, conditioned media were mixed with the reagent at a ratio of 2:1. The mixture was incubated at $4{ }^{\circ} \mathrm{C}$ for $16 \mathrm{~h}$ and centrifuged at $10,000 \times \mathrm{g}$ for $1 \mathrm{~h}$ at $4{ }^{\circ} \mathrm{C}$. The pellets were resuspended in $250 \mu \mathrm{L}$ of PBS, aliquoted and stored at $-80^{\circ} \mathrm{C}$ for further use.

\subsection{Characterisation of ELVs}

The amount of total protein in ELV samples was determined by Bradford assay (Sigma-Aldrich, Taufkirchen, Germany), measuring the absorption of $\lambda=595 \mathrm{~nm}$ light in a Tecan Infinite 200 PRO plate reader. The exosomal markers tetraspanins CD63 and CD9 were quantified by ELISA kits (Abbexa CD63 ELISA Kit and Abbexa MRP1 ELISA Kit, Cambridge, UK) according to the manufacturer's instructions.

The nanoparticle size distribution in isolated particle preparations was determined by dynamic light scattering (ZetaSizer Nano ZS, Malvern PANalytical, Malvern, UK). In short, $50 \mu \mathrm{L}$ of particle preparation was homogenised for 5 min using $30 \mathrm{G}$ needle. Ten microliters of preparation were mixed with $1990 \mu \mathrm{L}$ of PBS in analytical cuvettes, monitored in the analyser, and the data were processed by ZetaSizer Nano software (Malvern PANalytical, Malvern, UK).

ELV imaging was performed by transmission electron microscopy. Isolated particles were homogenised for 5 min with 30G needle and mixed with $4 \%$ paraformaldehyde at the ratio of 1:1. This solution was applied on carbon-coated Formvar copper meshes 
FCFT200-Cu-50 200 MESH (Sigma-Aldrich, Taufkirchen Germany). The meshes were fixed in 1.7\% glutaraldehyde solution for $5 \mathrm{~min}$, washed twice in deionised water for $2 \mathrm{~min}$, and stained with $2 \%$ uranyl acetate for $2 \mathrm{~min}$. After staining, the meshes were incubated with freshly prepared $2.25 \%$ methylcellulose and $2 \%$ uranyl acetate in a $v / v$ ratio of $4: 1$ for $10 \mathrm{~min}$ on an ice table. Prepared meshes were carefully dried on filter paper for 10 to $15 \mathrm{~min}$ and visualised using a transmission electron microscope Tecnai BioTwin Spirit G2 (FEI, Eindhoven, The Netherlands) on $80 \mathrm{kV}$ voltage. Electron microscope images were taken with a bottom-mounted 16 MP TEM CCD camera Eagle $4 \mathrm{~K}$ employing TIA (FEI, Eindhoven, The Netherlands).

\subsection{ELV Labelling for In Vitro and In Vivo Tracking}

ELVs were labelled with Alexa Fluor 555 dye (AF555) conjugated to oligonucleotides (BLOCK-it Alexa Fluor Red Fluorescent Control, Invitrogen, Thermo Fisher Scientific, Vilnius, Lithuania) by lipofection (RNAiMAX, Invitrogen, Thermo Fisher Scientific, Lithuania, Vilnius). Briefly, a mixture of $0.2 \mu \mathrm{M}$ of AF555-oligonucleotide conjugate was mixed with $3 \mu \mathrm{L}$ of RNAiMAX reagent in $100 \mu \mathrm{L}$ of the Opti-MEM ${ }^{\mathrm{TM}}$ medium Gibco $^{\mathrm{TM}}$, Thermo Fisher Scientific, Bleiswijk, The Netherlands) and incubated for $5 \mathrm{~min}$ at room temperature. Particle preparation ( $1 \mathrm{mg} / \mathrm{mL}$ of total protein) was added into lipofection mixture and incubated at $37^{\circ} \mathrm{C}$ for one hour. After incubation, unincorporated dye and residual micelles were removed using Exosome Spin Columns (Invitrogen, Thermo Fisher Scientific, Vilnius, Lithuania). For a micelle-cleaning efficiency assessment, the fluorescence intensity of lipofection mix comprising $0.2 \mu \mathrm{M}$ pmol AF555-oligonucleotide conjugate, 7.5 uL RNAiMAX reagent and $92.5 \mathrm{uL}$ of PBS was measured before and after cleaning procedure using Tecan Infinite Pro plate reader. The calculated efficiency of unincorporated dye elimination from ELV samples was $99.99 \%$ (Figure A2). After the labelling and cleaning procedure, the particles were concentrated using $100 \mathrm{~K} \mathrm{Amicon}{ }^{\circledR}$ ultra centrifugal filters (Merck Millipore, Darmstadt, Germany) and used for internalisation and tracking analysis.

\subsection{Intranasal In Vivo Administration of Airway ELVs}

All experimental procedures were performed on 4-month-old Balb/c mice according to the Law of the Republic of Lithuanian Animal Welfare and Protection (License of the State Food and Veterinary Service for working with laboratory animals No. G2-96). The mice were maintained and handled at the Lithuanian University of Health Sciences animal house in agreement with the ARRIVE guidelines. Before the intranasal administration of fluorescently labelled ELVs from poly (I:C)-primed and not primed airway cells, each nostril was treated with 100U hyaluronidase dissolved in $5 \mu \mathrm{L}$ PBS to increase the permeability of the mucus. After $30 \mathrm{~min}, 25 \mu \mathrm{L}$ of ELV solution containing $30 \mu \mathrm{g}$ of total protein was introduced to each nostril ( $60 \mu \mathrm{g}$ per mouse). The solution was administered gradually in $5 \mu \mathrm{L}$ portions followed by a 5 min interval and alternating the nostrils. After 1,2, 3, and $5 \mathrm{~h}$, the mice were anaesthetised and sacrificed, and the brains were further processed for immunohistochemical analysis.

\subsection{In Vitro Particle Tracking and Viability Assessment}

For ELV uptake in vitro evaluation, Alexa Fluor 555-labelled particle solution containing $0.5 \mathrm{mg} / \mathrm{mL}$ of total protein in PBS was applied on mixed glial and microglial cultures. After $20 \mathrm{~min}$ of incubation, Hoechst33342 $(6 \mu \mathrm{g} / \mathrm{mL}$, Thermo Fisher Scientific, Vilnius, Lithuania) was added to the incubation medium for visualisation of nuclei and isolectin GS$\mathrm{IB}_{4}$ from Griffonia simplificolia, Alexa Fluor ${ }^{\circledR} 488$ conjugate $\left(10 \mathrm{ng} / \mathrm{mL}\right.$, Molecular Probes ${ }^{\mathrm{TM}}$, Fisher Scientific, Vilnius, Lithuania) for staining microglial with microglial and mixed glial using fluorescence microscope Zeiss Axio Observer.Z1 (Carl Zeiss, Jena, Germany).

The viability of microglial cells in pure microglial cultures after ELV uptake was assessed by double nuclear staining with fluorescent dyes Hoechst33342 $(6 \mu \mathrm{g} / \mathrm{mL})$ and propidium iodide $(3 \mu \mathrm{g} / \mathrm{mL})$ for $10 \mathrm{~min}$ and imaging in a fluorescent microscope Olympus IX71 (Olympus Corporation, Tokyo, Japan). The images were taken by a 01-Exi-AQA-R-F- 
M-14-C camera (QImaging, Surrey, BC, Canada) and the image analysis was performed by the ImageJ software.

\subsection{Immunohistochemistry of Brain Tissue}

Animals were sacrificed by cervical dislocation; brains were removed, divided into two equal pieces along the longitudinal fissure. One part of each brain was snap-frozen in liquid nitrogen and stored for qPCR assay. Another part was washed in PBS and embedded in $4 \%$ paraformaldehyde solution for $30 \mathrm{~min}$. Afterwards, the brains were kept in $25 \%$ sucrose for $24 \mathrm{~h}$ at $4{ }^{\circ} \mathrm{C}$. Then, the tissue was frozen in liquid nitrogen and stored at $-80{ }^{\circ} \mathrm{C}$ until further processing. Next, serial coronal sections (20 $\mu \mathrm{m}$ thick) containing the substantia nigra were cut at $-23{ }^{\circ} \mathrm{C}$ using a cryostat (HM 560 Microm, Walldorf, Germany). The sections were mounted on glass slides (Plus, Menzel Glaser, Thermo Fisher Scientific, Vilnius, Lithuania), and allowed for complete dehydration in the cryostat chamber for $10 \mathrm{~min}$. Next, the slides were washed with PBS solution $(3 \times 10 \mathrm{~min})$ and stained with $0.5 \mathrm{mM} \mathrm{4} 4^{\prime}, 6$-diamidino-2-phenylindole (DAPI) for $5 \mathrm{~min}$ at room temperature for visualisation of the nuclei.

For microglial cell staining, the sections were subjected to $0.5 \%$ Triton X-100 permeabilisation for 40-60 $\mathrm{min}$ at room temperature in a dark, humid environment. After+ washing with PBS $(3 \times 10 \mathrm{~min})$, the sections were incubated with $1 \mu \mathrm{g} / \mathrm{mL}$ primary rabbit monoclonal antibodies against microglial transmembrane protein TMEM119 (RRID:AB_2800343, ab209064, Abcam) overnight at $4{ }^{\circ} \mathrm{C}$ and with AlexaFluor ${ }^{\circledR} 488$ conjugated chicken antirabbit IgG (Thermo Fisher Scientific, Vilnius, Lithuania) secondary antibodies diluted in PBS 1:200 for $2 \mathrm{~h}$ at room temperature. The slides were coated with anti-fading oil (Vectashield, Vector Laboratories, Burlingame, CA, USA), the edges were varnished with colourless nail polish. For negative control, PBS solution was added instead of primary antibodies, followed by secondary antibodies, and there was no fluorescence observed in the negative control samples. The stained tissue was visualised by laser scanning confocal microscope: Zeiss Axio Observer LSM 700 (Carl Zeiss Microimaging Inc., Jena, Germany).

The fluorescence intensity of AF555 signal and colocalisation analysis in brain slice micrographs was performed by ImageJ freeware. For each evaluation group, 12 micrographs of $320 \mu \mathrm{m} \times 320 \mu \mathrm{m}$ from 3 separate samples were assessed for the average signal strength intensity between the minimal-maximal values of 0 and 250 relative fluorescent units (RFU), respectively. The data are presented as averages \pm standard deviation.

\subsection{Evaluation of Intracellular and Intramitochondrial ROS}

Cytoplasmic and intramitochondrial ROS were evaluated as described in [28]. Briefly, the 2', $7^{\prime}$-dichlorofluorescein diacetate (DCFDA, Invitrogen, Thermo Fisher Scientific, Vilnius, Lithuania) was used to assess the formation of intracellular ROS in microglia. Microglial cells were seeded in 96-well plates (50,000/well) and cultivated for $24 \mathrm{~h}$. After incubation, cells were treated with poly (I:C)-primed and not primed airway cell ELVs $(10 \mu \mathrm{g} / \mathrm{mL}$ of total protein) for $16-18 \mathrm{~h}$, or with poly (I:C) for $1 \mathrm{~h}$. After incubation, all cells were washed with Hank's Balanced Salt Solution (HBSS, Gibco ${ }^{\mathrm{TM}}$, Thermo Fisher Scientific, Vilnius, Lithuania). Following washes, cells were stained with $10 \mu \mathrm{M}$ DCFDA for 30 min at $37^{\circ} \mathrm{C}$, repeatedly washed with HBSS and visualised using Olympus IX2-ILL100 fluorescence microscope (Olympus, Hamburg, Germany). For evaluation of mitochondrial superoxide, the cells were grown in clear 96-well plates the same way as for cytoplasmic ROS assessment. The cells were $3 x$ washed with HBSS and incubated with $2 \mu \mathrm{M}$ MitoSox ${ }^{\mathrm{TM}}$ Red (Thermo Fisher Scientific, Vilnius, Lithuania) in HBSS at $37^{\circ} \mathrm{C}$ in the dark for $15 \mathrm{~min}$. For positive control, the cells were treated with $100 \mu \mathrm{M}$ Antimycin A for $30 \mathrm{~min}$. The images were taken by fluorescent microscope Zeiss Axio Observer.Z1, and fluorescence intensity was evaluated by ImageJ software (National Institute of Health, Bethesda, MD, USA). 


\subsection{Real-Time Quantitative Reverse Transcription-PCR}

Gene expression level of antiviral response pathway cytokines was evaluated in mouse brains $24 \mathrm{~h}$ after intranasal delivery of poly (I:C)-primed airway ELVs and in cultured microglial cells after 24-h incubation with the same ELVs. Total RNA was isolated using TRIzol $^{\mathrm{TM}}$ reagent (Invitrogen, Thermo Fisher Scientific, Vilnius, Lithuania) according to the manufacturer's instructions. High-Capacity cDNA Reverse Transcription Kit (Applied Biosystems ${ }^{\mathrm{TM}}$, Thermo Fisher Scientific, Bleiswijk, The Netherlands) was used for cDNA synthesis after DNase (Thermo Fisher Scientific, Vilnius, Lithuania) treatment. Quantitative reverse-transcription PCR (qRT-PCR) applying SYBR Green I assay was used to analyse mRNA expression of inflammation markers: interleukin-6 (Il6), interferon beta-1 (Ifnb1), prostaglandin-endoperoxide synthase-2 (Ptgs2), chemokine (C-C motif) ligand 5 (Ccl5), interferon-alpha (Ifna), interleukin-1-beta (Il1b), tumour necrosis factor-alpha (Tnf), interferon-gamma (Ifng). Actin beta (Actb), glyceraldehyde 3-phosphate dehydrogenase (Gapdh) and RNA Polymerase II Subunit A (Polr2a) genes were used as endogenous controls for signal normalisation. PCR was carried out in a total volume of $12 \mu \mathrm{L}$ and consisted of $6 \mu \mathrm{L}$ of Power SYBR ${ }^{\mathrm{TM}}$ Green PCR Master Mix (Applied Biosystems ${ }^{\mathrm{TM}}$, Thermo Fisher Scientific, Bleiswijk, The Netherlands), $15 \mathrm{ng}$ of cDNA, and $0.25 \mu \mathrm{M}$ of each primer and nuclease-free water. Real-Time PCR System "Applied Biosystems 7500 Fast" (Applied Biosystems $^{\mathrm{TM}}$, Thermo Fisher Scientific, Bleiswijk, The Netherlands) used for products amplification and fluorescent signal registration. Comparative $2^{-\Delta \Delta C T}$ method was used to evaluate inflammation markers expression in poly (I:C)-primed airway ELVs-treated samples compared to those treated with not primed ELVs.

\subsection{Statistical Analysis}

Statistical analysis was performed using Sigma Plot v12.5 software (Systat Software Inc., Berkshire, UK). The means of the experimental data are presented with standard errors. Statistical comparisons of the two groups were performed using Student's $t$-test. Multiple groups were compared using and one-way analysis of variance (ONE WAY ANOVA) with Bonferroni statistical criterion. Differences between means were considered statistically significant at $p<0.05$.

\section{Results}

\subsection{Identification and Characterisation of Airway Cell ELVS}

At first, ELVs isolated from poly (I:C)-primed and not primed rat airway cell-conditioned medium were evaluated for morphology by transmission electron microscopy (TEM). The samples contained vesicles of approximately 10-190 nm in diameter (Figure 2a,d).

The dynamic light scattering analysis revealed that the particle diameter in samples ranged from 10 to $160 \mathrm{~nm}$, and 98 per cent of the particles in the samples were in the range of 30-150 nm, which is characteristic for exosomes (Figure 2b,e). Next, particle preparations were ELISA-tested for common exosomal markers, tetraspanins CD9 and CD63. The analysis confirmed both markers present in the samples; however, CD63 was found about five times more than CD9 (Figure 2c). Similar characteristics were found by examining ELV preparations from mice airway cell cultures; however, in contrast to the rat samples, CD9 marker predominated (Figure 2f). There were no detectable differences in morphology, size distribution and CD63/CD9 presence found between poly (I:C)-primed and not primed airway cell exosomes (data not shown). 


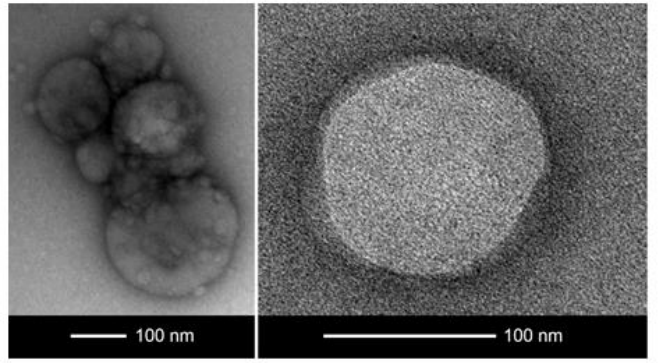

(a)

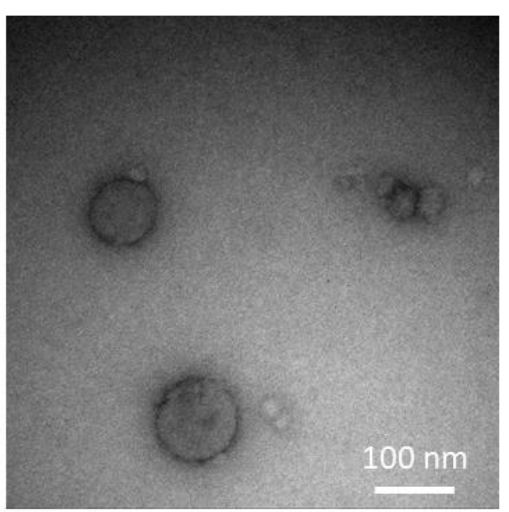

(d)

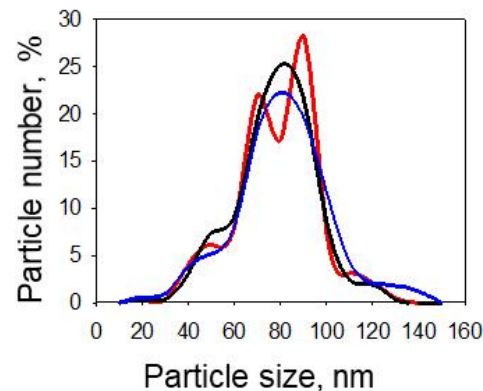

(b)

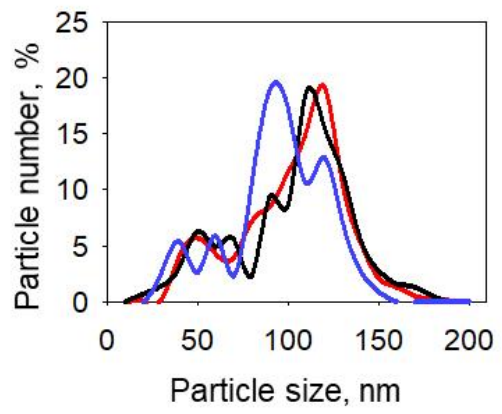

(e)

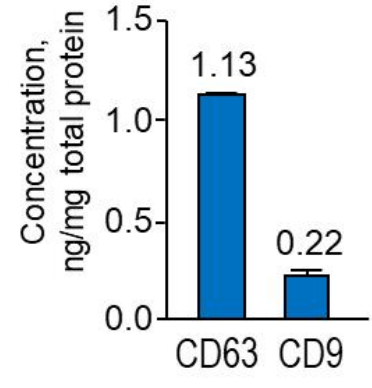

(c)

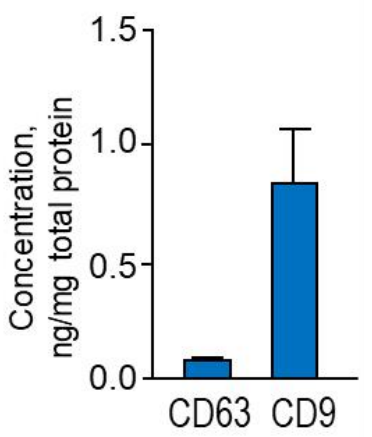

(f)

Figure 2. Poly (I:C)-treated rat $(\mathbf{a}-\mathbf{c})$ and mouse $(\mathbf{d}-\mathbf{f})$ airway cell ELV morphology, particle size distribution and specific markers. Representative transmission electron microscopy images (a,d), dynamic light scattering nanoparticle analysis data of three exosome samples (b,e) and tetraspanin CD63 and CD9 content per total exosome preparation protein determined by $\operatorname{ELISA}(\mathbf{c}, \mathbf{f})$.

\subsection{Poly (I:C)-Primed Airway ELV Tracking in the Brain}

For blood-brain barrier penetration monitoring, Alexa Fluor-555 (AF555) labelled ELVs from poly (I:C)-primed and not primed airway cells were introduced intranasally to mice. Red fluorescence became visible in the brain (middle section of coronal plane slices) already $1 \mathrm{~h}$ after treatment, and later (after 3 and $5 \mathrm{~h}$ ), the fluorescence spots became more extensive (Figure 3a). Some of them resembled cell body shape suggesting that particles were internalised by specific cells at this time point. Interestingly, some brain regions, such as the hippocampal pyramidal neuron layer, were more prone to collect ELVs (Figure 3b). In the slices from the olfactory bulb (Figure 3c), it was no specific particle clustering, but the cell-shaped AF555-positive staining was present already after $1 \mathrm{~h}$ of the ELV delivery. We did not detect visual differences between particle distribution in the brains treated with poly (I:C)-primed and not primed airway ELVs. Additionally, there was no red staining visible in brain slices from mice that did not receive ELV treatment ( 0 h image in Figure $3 a)$.

The quantitative evaluation of AF555 fluorescence intensity after 1, 3 and $5 \mathrm{~h}$ revealed a significant signal increase from about 1 relative fluorescent unit (RFU) at time point "zero" up to about 5 RFUs after $1 \mathrm{~h}$ and further grew to about 7 RFUs after $3 \mathrm{~h}$ (Figure $3 \mathrm{~d}$ ). However, there was no significant AF555 fluorescence signal increase in the ELV treated brain samples after $5 \mathrm{~h}$ compared to those after $3 \mathrm{~h}$. Additionally, no significant differences between brains treated with poly (I:C)-primed and unprimed airway cell ELVs at each time point. 

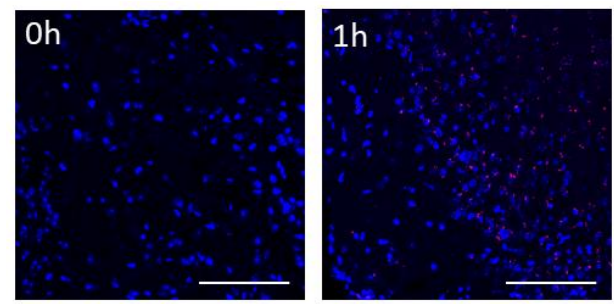

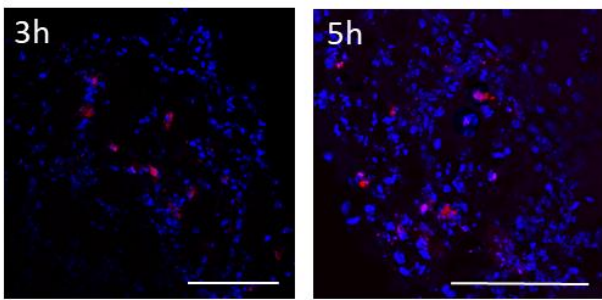

(a)

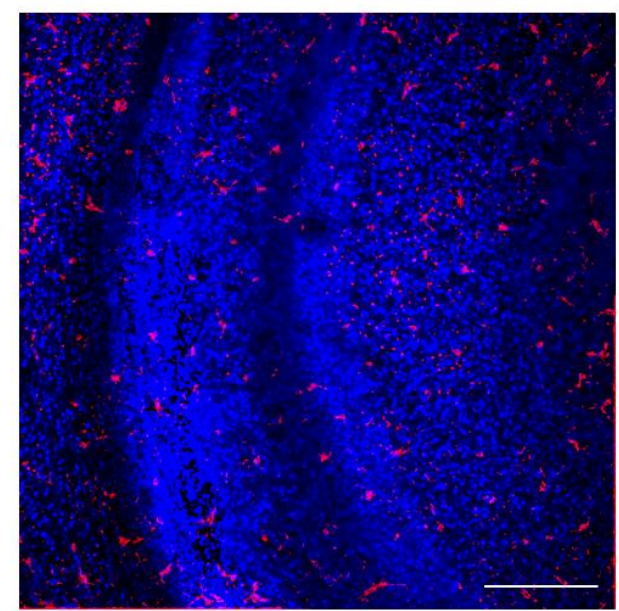

(c)

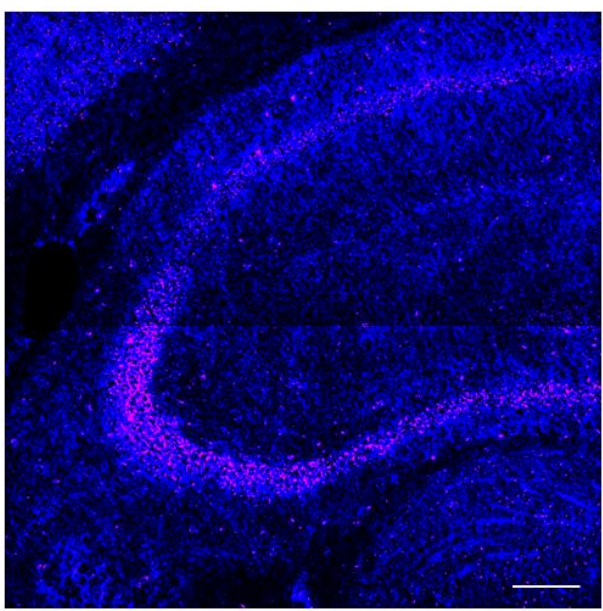

(b)

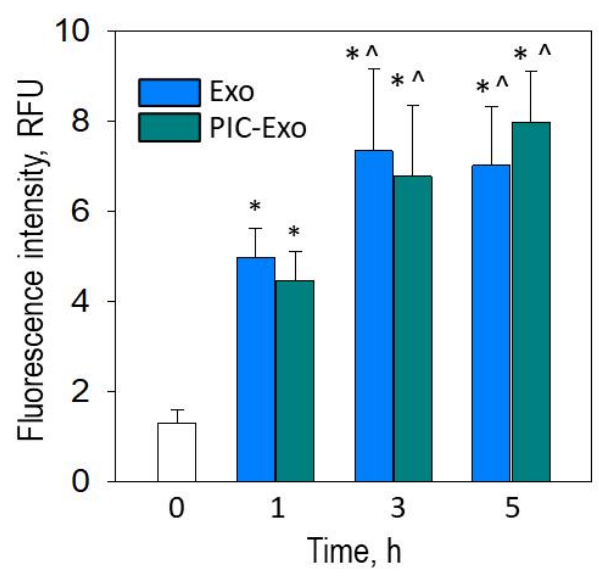

(d)

Figure 3. ELVs from poly (I:C)-treated airway cells in mouse brain coronal slices from central section after $0,1,3$, and $5 \mathrm{~h}$ following intranasal introduction (a). In (b) - quantitative evaluation of-AFF555 fluorescence intensity in brain slice micrographs $3 \mathrm{~h}$ after intranasal administration of the stained particles. The data are expressed as averages \pm standard deviation of 3 independent experiments that involved three animals in each experimental group; the fluorescence intensity was evaluated in 12 images for each separate animal sample. PIC-Exo is for poly (I:C)-primed airway ELVs, Exo-not primed airway ELVs, and controls brains from mice without treatment. * indicates statistically significant difference compared to the Control when $p<0.001, \wedge$ - compared to Exo or PIC-Exo, respectively, after one hour, when $p<0.05$. In (c,d), there are ELVs in the olfactory bulb, prefrontal cortex and hippocampus slices, respectively, one hour after intranasal introduction. Particles loaded with RNR-conjugated AF555 are red, and nuclei are stained blue with DAPI. Scale bar $100 \mu \mathrm{m}$.

Next, the brain slices were immunostained for TMEM19 to determine if the ELVs were internalised by microglial cells. The staining revealed that most particles colocalised with microglial cell bodies (Figure 4a, upper image row) or their processes (zoomed-in ROI in the lower image row of Figure $4 \mathrm{a})$. 

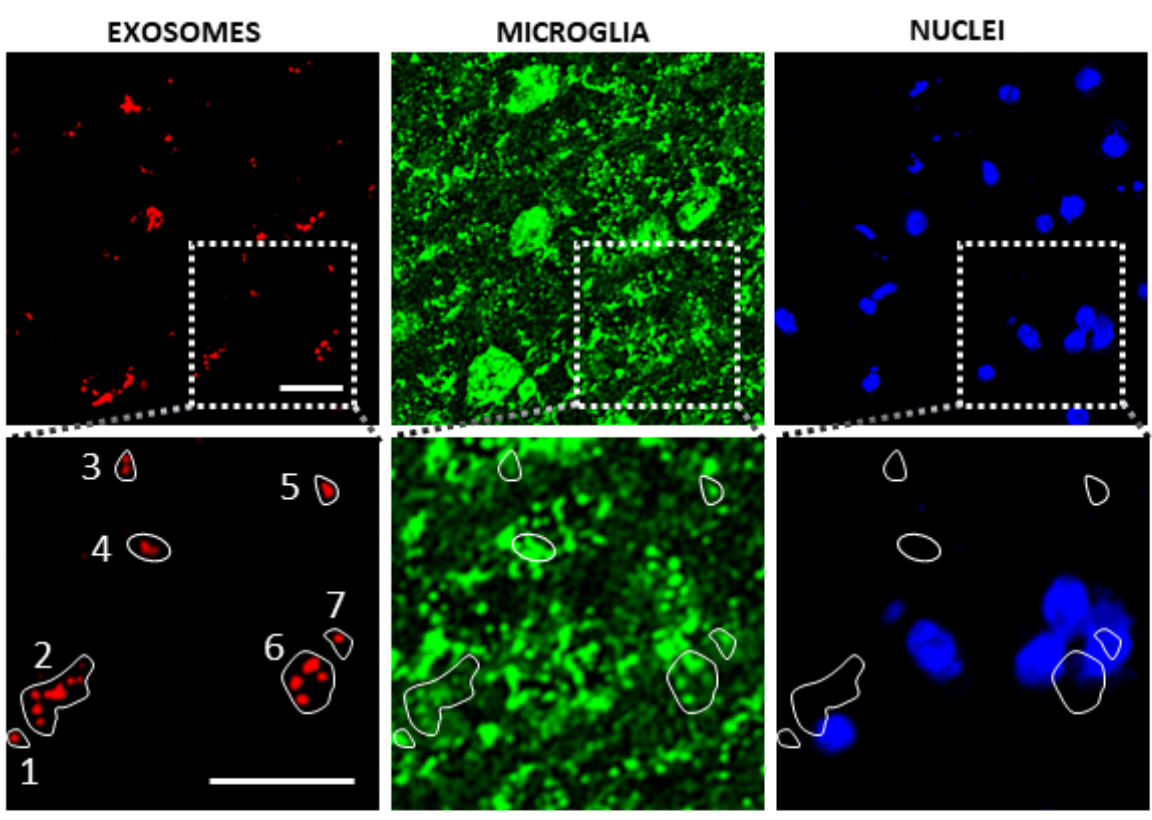

(a)

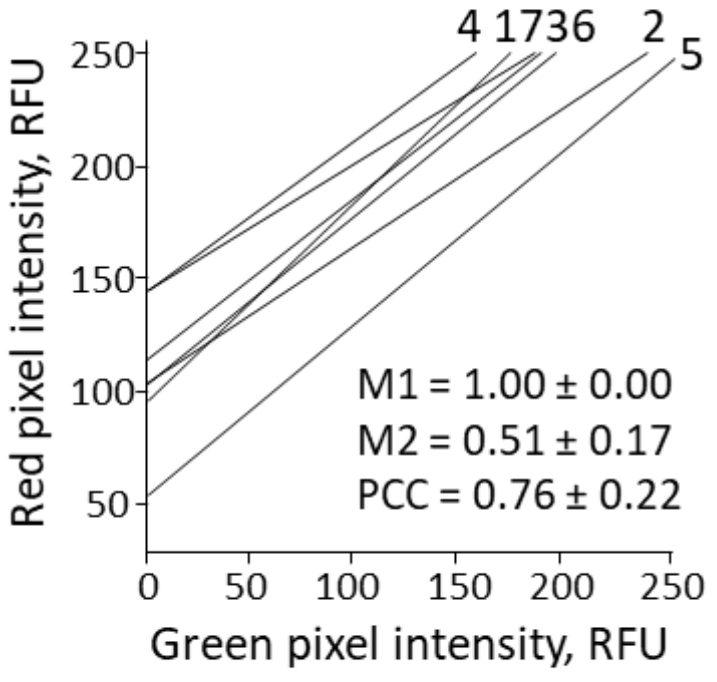

(b)

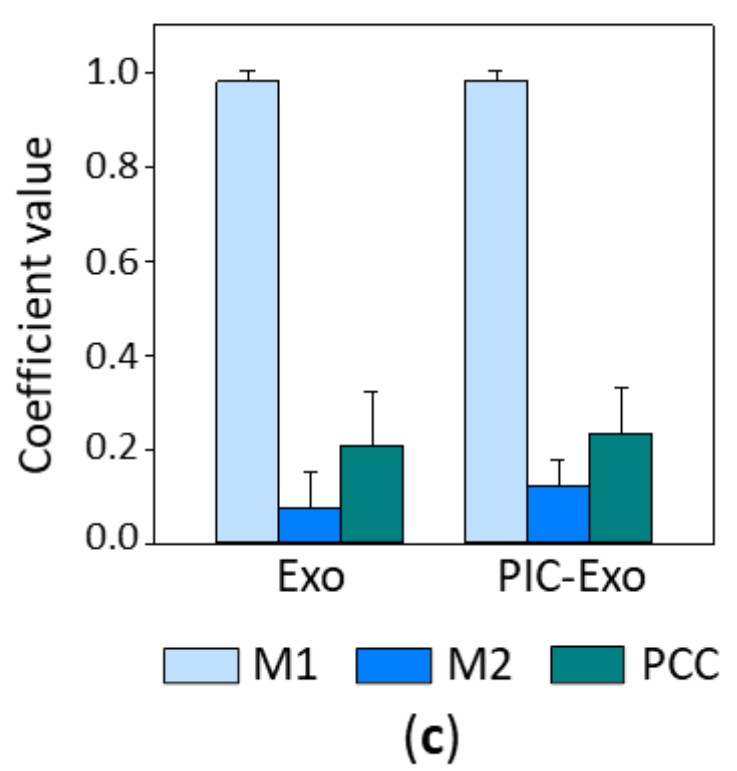

Figure 4. Poly (I:C)-treated airway ELV internalisation by microglia in mouse brain $2 \mathrm{~h}$ after intranasal introduction. In (a), a representative brain slice image, where particles loaded with RNR-conjugated AF555 are red, nuclei are stained blue with DAPI, and microglial cells are green, visualised by immunostaining against TMEM119. White arrows indicate microglial cell bodies with colocalised ELVs (upper image row, MERGED), and particles colocalising with microglial processes is visible in the zoomed ROI image (lower image row). The scale bar is $20 \mu \mathrm{m}$. Colocalisation analysis in seven small ROIs indicated by the white lines was performed by ImageJ plugin JACoP; cytofluorograms, Mander's and Pearson's coefficient values are presented in (b). Results of colocalisation analysis in full-size images are shown in (c), n = 15. M1-Mander's overlapping coefficient showing the red fluorescence fraction overlapping the green, M1-the green fraction overlapping the red; PCC-Pearson's correlation coefficient. Exo-images of the slices from brains treated with ELVs from control airway cells; PIC-Exo-from poly (I:C)-treated airway cells.

The colocalisation analysis of the ROI marked by the white line in the zoomed (lower) image row revealed a strong correlation between ELV and microglial staining (Figure $4 \mathrm{~b}$ ). The diagonal positioning of cytofluorograms and close to 1 Pearson's correlation coefficient (PCC) indicates a similar distribution of red (ELVs) and green (microglia) pixel intensity. Mander's 1 coefficient (M1) value is 1.00, and this means that all the AF555- 
positive area completely overlaps with the AF488-positive area. Similarly, the values of M1 were found close to 1 in all examined images of brain slices after intranasal delivery of the ELVs (Figure 4c). The values of PCC in the full-size images were not as high as in the ROI analysis, and this can be explained by the considerable difference between the red and green fluorescence areas.

Overall, the immunohistochemistry data indicate that airway cell ELVs, after intranasal delivery, enter the brain within hours and are actively internalised by microglial cells.

\subsection{Poly (I:C)-Primed Airway ELV Tracking in Glial Cell Cultures}

In vitro experiments of internalisation of Alexa Fluor-555 (AF555) labelled ELVs from poly (I:C)-primed and not primed airway cells in cultivated rat pure microglial and mixed glial cultures confirmed that microglial cells internalise particles more rapidly than astrocytes. All particles were entirely relocated to microglial cells $30 \mathrm{~min}$ after addition to the culture medium in both pure microglial and mixed glial cultures (Figure 5). The ELVs looked as if they collected into cytoplasmic vesicles suggesting that the uptake pathway was either endocytosis, phagocytosis, or micropinocytosis. Such particle internalisation did not affect the viability of microglial cells; double nuclear fluorescent staining with Hoechst 33342 and propidium iodide revealed no significant difference in viable cell number between ELV-treated and untreated, as well as between poly (I:C)-primed and not primed airway ELV-treated microglial cultures; the percentage of viable cells in all cultures were above $98 \%$ (Figure A3).
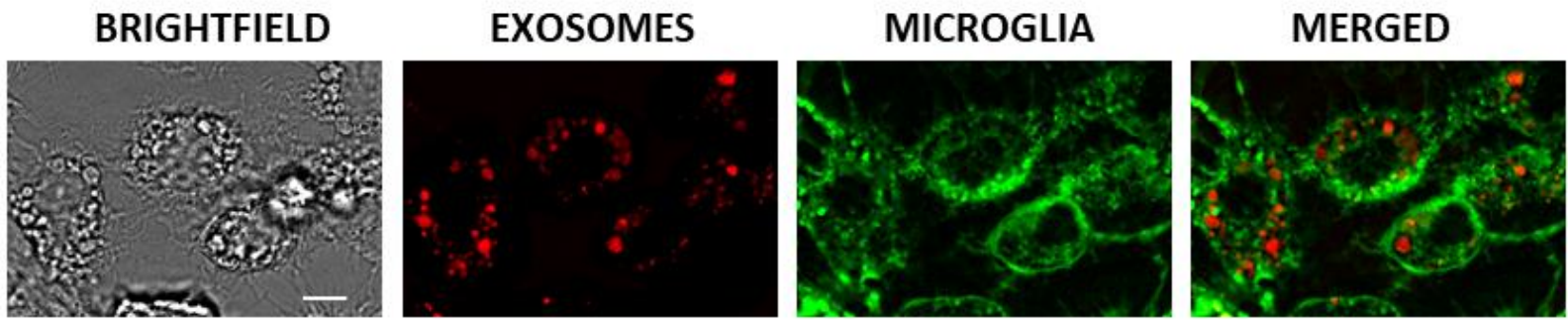

(a)
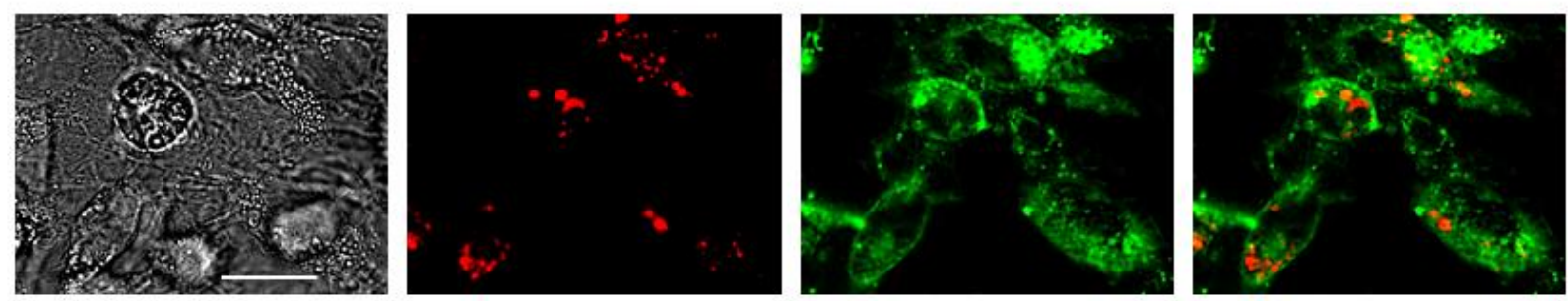

(b)

Figure 5. Poly (I:C)-treated airway cell ELV internalisation by microglia in and in pure microglial (a) and mixed rat (b) glial cultures 30 min after treatment. Particles loaded with RNR-conjugated AF555 are red, nuclei are stained blue with Hoechst33342, and microglial cells are green, stained with AF488-conjugated isolectin B4. The scale bar in (a) is $10 \mu \mathrm{m}$ and in (b) $-50 \mu \mathrm{m}$.

\subsection{Poly (I:C)-Primed Airway Cell ELVs Impact on ROS Formation in Microglia}

Mitochondrial and cytoplasmic ROS act upstream of the inflammatory cascade during viral infection and play a crucial role in immune memory formation [29-31]. To determine whether poly (I:C)-primed airway ELVs affect mitochondrial and cytoplasmic ROS production, microglial cells were incubated with the ELVs for 16-18 h, loaded with either MitoSOX ${ }^{\mathrm{TM}}$ or DCFDA and monitored under a fluorescent microscope. 
Both visual monitoring and quantitative evaluation of the micrographs revealed that poly (I:C)-stimulated airway cell ELVs significantly increased the formation of mitochondrial ROS in microglial cells (Figure 6a). After $24 \mathrm{~h}$, the MitoSOX ${ }^{\mathrm{TM}}$ fluorescence intensity was by $31 \%$ higher compared to the samples treated with untreated airway cell ELVs. Moreover, the increased level of mitochondrial ROS in poly (I:C)-primed airway cell ELV-treated samples remained even after $48 \mathrm{~h}$ after the treatment. Additionally, ELVs from poly (I:C)-primed airway cells significantly increased the formation of cytoplasmic ROS in microglia; the DCFDA fluorescence level after $24 \mathrm{~h}$ post-treatment rose by $14 \%$ (Figure $6 \mathrm{~b}$ ). However, there was no significant difference in MitoSOX ${ }^{\mathrm{TM}}$ and DCFDA fluorescence intensity between untreated control $(100 \%)$ and samples treated with ELVs from airway cells unaffected by poly (I:C).

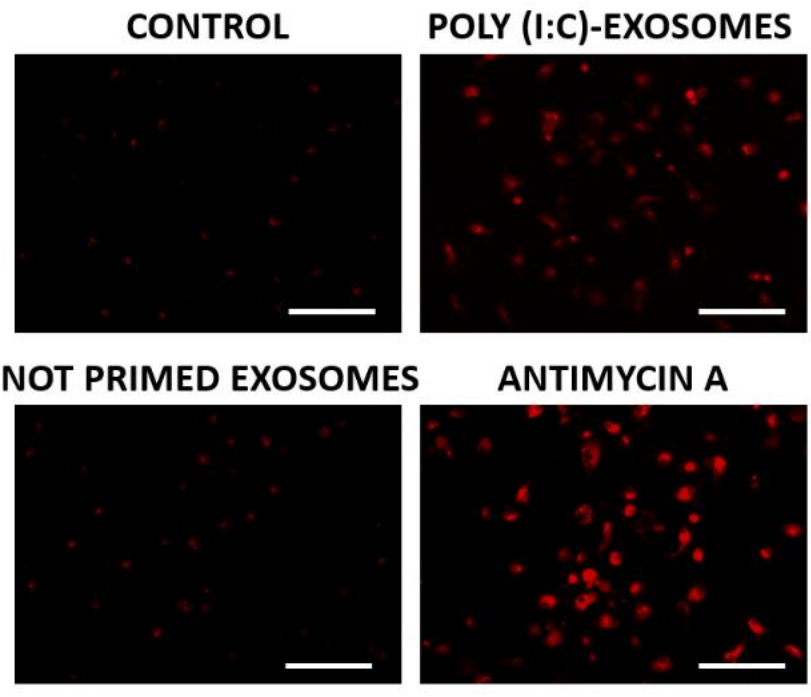

MITOCHONDRIAL ROS

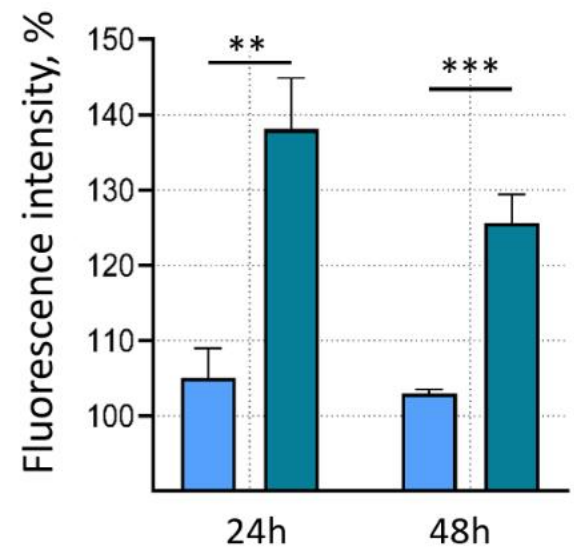

(a)

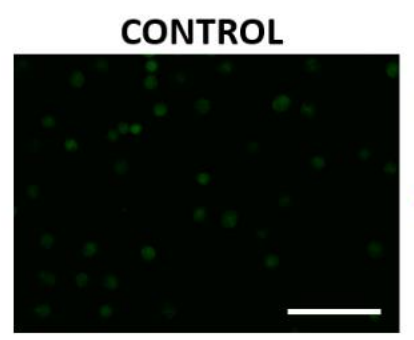

POLY (I:C )-EXOSOMES
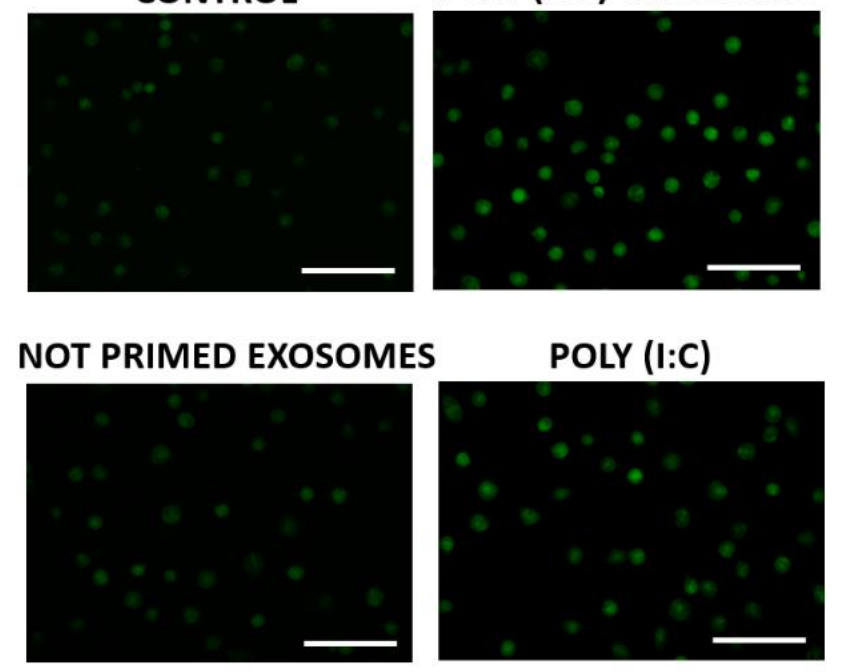

\section{POLY (I:C)}

Untreated airway exosomes

Poly (I:C)-treated airway exosomes

CYTOPLASMIC ROS

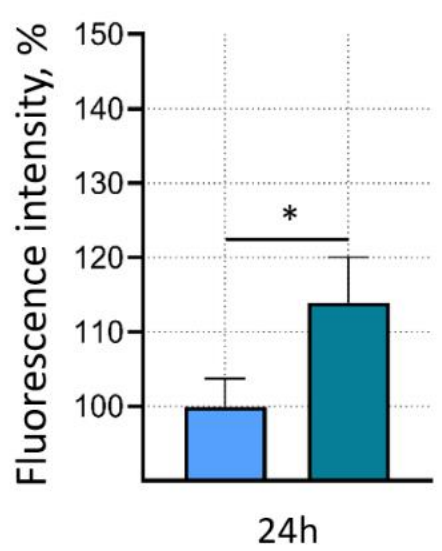

(b)

Figure 6. Intramitochondrial and cytoplasmic reactive oxygen species (ROS) formation in microglia after treatment with ELVs from poly (I:C)-primed airway cells. Cytoplasmic ROS were detected by DCFDA assay and mitochondrial superoxideby MitoSOX ${ }^{\mathrm{TM}}$ fluorescence. (a)-representative images and quantitative evaluation of MitoSOX fluorescence in cultured microglia. For positive control of the assay, $100 \mu \mathrm{M}$ Antimycin A was used. The scale bar is $100 \mu \mathrm{m}$. (b) -representative 
images and quantitative evaluation of 2,7-dichlorofluorescein (derived from DCFDA) fluorescence in microglial cultures. For positive control of the assay, $1 \mu \mathrm{g} / \mathrm{mL}$ poly (I:C) was used. The scale bar is $100 \mu \mathrm{m}$. The quantitative data of ROS-dependent fluorescence intensity in micrographs are presented as percentage of untreated control and expressed as averages \pm standard deviation of 3 experiments in 3 biological replicates. ${ }^{* * *}$ indicates statistically significant difference when $p<0.001$; $* *-p<0.01 ; *-p<0.05$.

\subsection{Antiviral Inflammatory Response Related Cytokine Expression in Brain and Cultured Microglia after Treatment with Poly (I:C)-Primed Airway Cell ELVs}

An increase in ROS production by poly (I:C)-primed airway ELVs in cultured microglial cells suggested they could be inflammatory activated. Therefore, the next step in the study was to test whether virus mimetic poly (I:C)-treated ELVs might stimulate expression of inflammatory cytokines involved in the antiviral inflammatory response in brain tissue and microglial cell cultures. The next day after in vivo intranasal treatment with poly (I:C)-primed airway ELVs, the average level of mRNA of Ifna, Ifng, Ccl5, Il1b, Tnf, and Ptgs 2 tended to increase compared to the level in brains treated with not primed airway ELVs and reaching statistically significant difference for Ptgs2 (Figure 7a). A similar tendency was observed in microglial cultures after 24-h treatment with poly (I:C)-primed airway ELVs, with a statistically significant increase in Ccl5 mRNA level (Figure 7b).

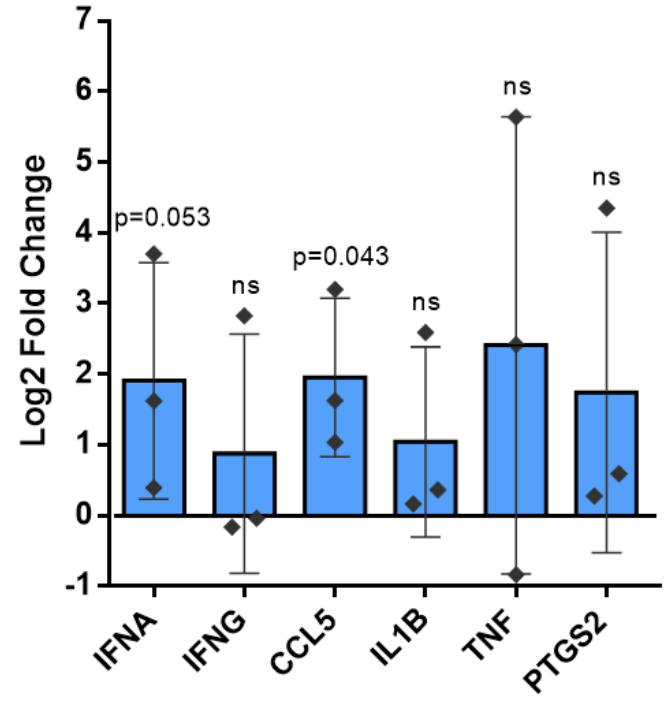

(a)

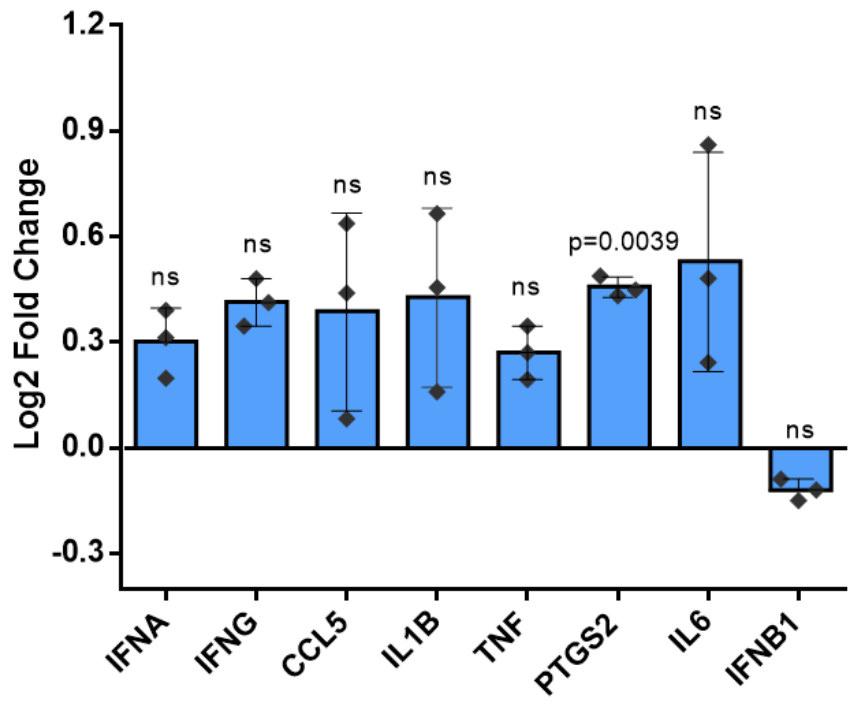

(b)

Figure 7. Expression of mRNA of inflammation markers after poly (I:C)-primed airway ELV treatment in (a) brain tissue and (b) cultured rat microglial cells. Data are given as log2 Fold Change $\left(2^{-\Delta \Delta C T}\right)$ calculated from control specimens treated with unprimed ELVs. Statistical differences of markers expression between control specimens and specimens treated with poly (I:C)-primed airway ELVs calculated applying unpaired $t$-test; $p<0.05$ considered significant. Bar plot represent mean of 3 experiments and whiskers—standard deviation; ns-not significant. Ifna is for interferon-alpha gene, Ifng-interferon-gamma, Ccl5-chemokine (C-C motif) ligand 5, or Rantes, Il1b —interleukin-1-beta, Tnf - tumour necrosis factor-alpha, Ptgs2 - prostaglandin-endoperoxide synthase-2, Il6 -interleukin-6, Ifnb1—interferon beta-1.

To summarise, ELVs derived from airway cells affected by virus mimicking poly (I:C) sequence tend to elevate antiviral response cytokine expression both in the brain after intranasal delivery and in cultured microglia after cell culture medium.

\section{Discussion}

The main highlights of the present study include confirmation that (1) airway cell ELVs easily penetrate the blood-brain barrier of healthy laboratory mice and (2) are quickly (within an hour or two) internalised by microglial cells. Moreover, (3) the ELVs from airway cells after viral infection mimicking priming induce specific changes in microglial cells, 
leading to increased intracellular and intramitochondrial ROS generation. Finally, (4) the ELVs stimulate inflammatory cytokine expression in the brain and microglia.

Upper respiratory tract infections result in 10 million outpatient visits per year, and $70-90 \%$ of these infections are of viral origin [32,33]. Viral infections promote innate or nonspecific and acquired or specific immune responses. There is a well-established correlation between peripheral viral infection and neuroinflammation, leading to neurodegeneration $[34,35]$. The recently emerged SARS-CoV-2 virus that caused COVID-19 pandemic is also not an exception from this point of view; there are numerous reports about neuroinflammation-related central nervous system damage caused by this infection [36]. However, the mechanisms transmitting inflammation from the periphery to the brain remains elusive.

One of the most suggestable candidates for inflammation transmission from the periphery to the brain is exosomes. Exosomes of cells affected by bacteria, viruses, parasites, or fungi carry pathogen components that can be transferred to other cells [37]. For example, exosomes produced by bacterial infection-affected macrophages contain pro-inflammatory factors that activate $\mathrm{B}$ and $\mathrm{T}$ lymphocytes enhancing the immune response $[38,39]$. Virustreated cells contain viral proteins and RNA that cause inflammatory response or even infection in recipient cells [37]. Herpes simplex, hepatitis A, B, C, and human immunodeficiency (HIV) viruses can spread through exosomes [40-43]. The above-listed evidence allows assuming that some of the exosomes produced by infected cells could penetrate the central nervous system and cause neuroinflammation. Although several studies report peripheral exosomes crossing the blood-brain barrier [41,42], their further cellular uptake remained unknown. In addition, none of the examined exosomes originated from airway epithelium or fibroblasts. Our study experimentally demonstrated fast brain uptake of airway epithelial ELVs and provided evidence about their localisation in microglial cells. In addition, the in vivo data were supported by in vitro experimental proof of much faster ELV uptake performance by microglia compared to astrocytes. Although this is not direct evidence of airway infection spreading to the brain, the study gives a solid reason and background for studying this possibility. Interestingly, there were visually more airway cell ELVs in the pyramidal neuron area of the hippocampus after intranasal introduction. Hippocampal neurons are the primary target of Alzheimer's disease, and the cause of such selective damage to this area remains unknown. The fact that the hippocampus selectively collects peripheral ELVs carrying inflammatory mediators suggests a new hypothesis for Alzheimer's disease development. The hippocampus and olfactory regions are anatomically close; they are connected by memory formation networks and participate in glymphatic brain clearance $[44,45]$. Such anatomical and functional relations likely favour ELVs transmission from the nasal cavity. Similar to our findings, microglial localisation of intravenously injected fluorescently labelled exosomes was observed by $\mathrm{Li}$ and colleagues [46]. The authors have found that exosomes from serum of LPS-treated mice initiate inflammation in the brains of healthy exosome recipients. Additionally, an in vivo study by Zhuang with co-authors demonstrates fast uptake of exosomes (but not microvesicles) from three different cancer cell lines and embryonic fibroblasts by brain and microglia [47].

Despite showing ELV relocation from the nasal cavity to the brain cells, we did not progress the understanding of the mechanism of EV entrance to the CNS. A recent review by Saint-Pol and colleagues suggest at least five possible theoretical interactions of the peripheral exosomes with the blood-brain barrier forming cells: (i) association with a protein G-coupled receptor on the cell surface, (ii) adhesion to the cell surface and fusion, releasing the EV content in the cytoplasm, (iii) micropinocytosis, (iii) nonspecific/lipid raft formation, and (iv) receptor-mediated transcytosis [8]. Banks and co-authors discovered that intravenously introduced exosomes from mouse, human, cancerous, and non-cancerous cell lines all cross the blood-brain barrier, but at different rates and by distinct mechanisms: adsorptive transcytosis and mannose 6-phosphate receptor [6]. Furthermore, both in vivo and in vitro experiments confirm a substantial increase in the barrier permeability for 
exosomes in the presence of inflammatory stimuli such as bacterial LPS or TNF $\alpha[6,48]$. Such findings strongly suggest that peripheral EVs might be important yet underestimated players in neuroinflammation.

Exosome researchers inevitably have to deal with certain limitations of the investigation tools, and this study was not an exception. A significant limitation is the lack of reliable and straightforward isolation techniques to collect enough exosomes for investigation and avoid impurities such as proteins, lipid particles and other extracellular vesicles [49]. Usually, a relatively pure sample means low gain and vice versa [50,51]. In addition, the characteristics of the exosome population, such as dominant particle size, biomarker content and biological efficiency, might vary depending on chosen isolation procedure $[52,53]$. The polymer precipitation method of EV isolation applied in this study for simplicity and gain is characterised as a high-yield-low-purity method. This might raise the possibility that some part of the biological activity of the preparation might be attributed to the non-exosomal contaminants in the preparation. Another important limitation is a lack of specific exosome identification procedures. There is a common practice to identify exosomes by size in a nanoparticle tracking analyser, by morphology (electron microscopy, usually transmission electron microscopy that allows visualising lipid bilayer of the exosomal membranes) and by specific markers. However, even if each of the steps confirms exosome-like qualities, there is still possible that some particles in the preparation are of different origin than exosomes [54,55]. Therefore, the hypothesis of the study would be suggested to reconfirm after a while when more specific markers and high yield-high-purity exosome isolation assays are elaborated.

This study demonstrated that ELVs from virus mimetic-treated airway cells stimulate ROS generation in cultivated microglia. We have applied two different assays for ROS evaluation. Conversion of DCFDA to fluorescent 2,7-dichlorofluorescein (DCF) indicates hydroxyl, peroxyl and some other species produced into cell cytoplasm [56]. Mitochondrially targeted MitoSOX ${ }^{\mathrm{TM}}$ Red, in its turn, reports about the intensity of generation of superoxide radicals within mitochondria. Of all ROS, the respiratory chain primarily produces superoxide, which cannot cross membranes and remains where made unless converted to hydrogen peroxide by superoxide dismutase. Hydrogen peroxide molecules penetrate mitochondrial membranes to the cytosol, where it often undergoes further conversions depending on the chemical environment, e.g., to hydroxyl radical by Fenton reaction. Thus, mitochondrial superoxide could also be the source of cytoplasmic ROS detected by the DCFDA reaction. The fact that poly (I:C)-primed airway ELVs stimulated mitochondrial superoxide generation far more intensively than intracellular (cytoplasmic) ROS strongly suggests mitochondria were the primary source of radicals in this case. However, more experimental evidence is required to prove this hypothesis, such as testing how microglial cytoplasmic ROS levels induced by poly (I:C)-primed airway ELVs would be affected by the presence of mitochondrial superoxide scavenger mitoTEMPO.

Reactive oxygen species, including those from mitochondria, are generated as a fast response to infection $[29,57]$. Mitochondrial ROS lie at the top of the innate immune response cascade and precedes ROS generation from phagocytosis-related NADPH oxidase [58]. Moreover, they are required for virus-induced mitochondrial antiviral signalling protein (MAVS) to activate inflammasome [59,60], which is directly linked to neurodegeneration according to recent research $[61,62]$. Such an important role of mitochondrial ROS in inflammatory response indicate the following landmarks in dissecting the role of virus-primed airway cell ELVs, such as examining their effect on the mitochondrial and glycolytic profile of microglial cells, inflammasome activation and impact on the inflammatory cytokine level in the brain.

The critical finding of the study is the increased level of expression of antiviral inflammatory response marker CCL5, or Rantes, in the brain. Interferons alpha and gamma belong to different interferon groups, and both are known to activate the NFkappaB pathway, which stimulates CCL5, IL- $1 \beta$ and TNF- $\alpha[63,64]$. Thus, the results suggest that at least one of the pathways might be stimulated by poly (I:C)-primed airway ELVs. The 
type I pathway is well known to be directly activated by the TLR3 [65]. However, there is a report that this receptor might also trigger the interferon type II pathway [66]. Such evidence suggests that ELVs from poly (I:C)-treated airway cells carry some TLR3 agonist, possibly, poly (I:C) itself. Indeed, poly (I:C) was transferred in extracellular vesicles of U937 macrophages, and such vesicles mimicked the direct effect of poly (I:C) on synovial fibroblasts [67]. Therefore, it is very likely that poly (I:C) was also among the cargo of the airway cell ELVs examined in this study. Interestingly, a transcription of a gene involved in cyclooxygenase-prostaglandin inflammatory signalling PTGS2 was significantly activated in cultured microglia after poly (I:C)-primed airway ELV treatment. The PTGS2 pathway modulates the extend of antiviral response and might play a significant role in autoimmune disease development [68]. Of note, this enzyme plays an essential role in Parkinson's and Alzheimer's disease-related neurodegeneration [69,70]. Overall, the elevated levels of cytokine expression after treatment with ELVs from virus mimetic-primed airway cells provides new hallmarks for investigation of peripheral-central nervous system vesicular communication, such as determining the exact signalling sequence and actual protein levels, detecting differences between such signalling induced by different viruses, and examining correlations with neurodegenerative signalling pathways. Additionally, elucidating the mechanism of ELV crossing the blood-brain barrier under the ordinary and infection-affected conditions and identifying the virus-induced molecular profile of airway cell ELVs would be of great importance in understanding the role of these extracellular vesicles in communication between the periphery and brain during viral infections.

\section{Conclusions}

- Virus mimetic poly (I:C)-primed and not primed airway cell ELVs reach brain tissue after not more than an hour from the intranasal introduction in mice.

- Both in the brain and culture, airway cell ELVs are internalised by microglial cells faster than by other cell types, such as astrocytes.

- Poly (I:C)-primed airway exosomes induce a significant and lasting increase in cytoplasmic and intramitochondrial ROS production. Conversely, the exosomes from not primed airway cells do not cause changes in ROS levels.

- Poly (I:C)-stimulated airway exosomes significantly stimulate expression of inflammatory factors Ccl5 (in brain) and Ptgs2 (in cultured microglia).

Author Contributions: Conceptualisation, L.J., R.M. and A.J.; methodology, D.K., L.J., N.P., Z.M., Z.B., G.S. and A.J.; formal analysis, D.K., O.J., L.J., H.I. and I.S.; investigation, D.K., D.N., O.J., L.J., A.M., N.P., J.Š., H.I., Z.M., I.S. and G.S.; writing — original draft preparation, D.G. and A.J.; writingreview and editing, D.G., N.P., R.M., D.H.P. and A.J.; visualisation, D.K., D.G. and G.S.; supervision, D.H.P., R.M. and A.J. All authors have read and agreed to the published version of the manuscript.

Funding: The study is a part of the EXOTARGET project funded by a grant No. 01.2.2-LMT-K-71801-0036 from the Research Council of Lithuania.

Institutional Review Board Statement: The study was conducted according to the guidelines of the Declaration of Helsinki, and approved by the Lithuanian Food and Veterinary Service (protocol code G2-96, 14 November 2018).

Informed Consent Statement: Not applicable.

Data Availability Statement: The raw data supporting the conclusions of this manuscript will be made available by the authors, without undue reservation, to any qualified researcher.

Conflicts of Interest: The authors declare no conflict of interest. 


\section{Appendix A}

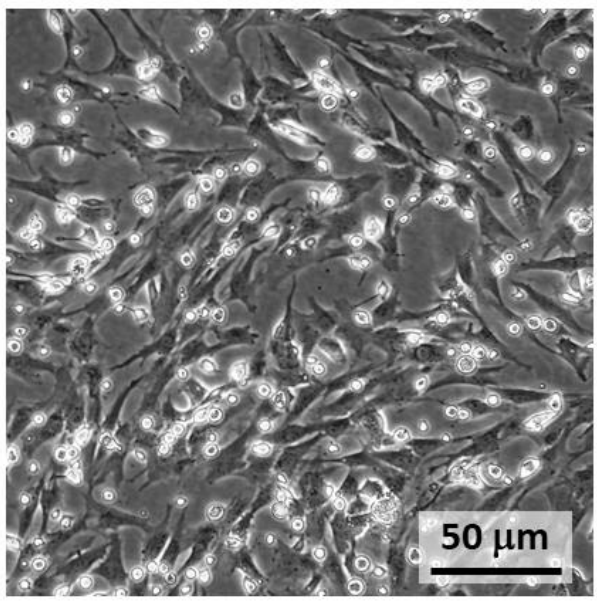

(a)

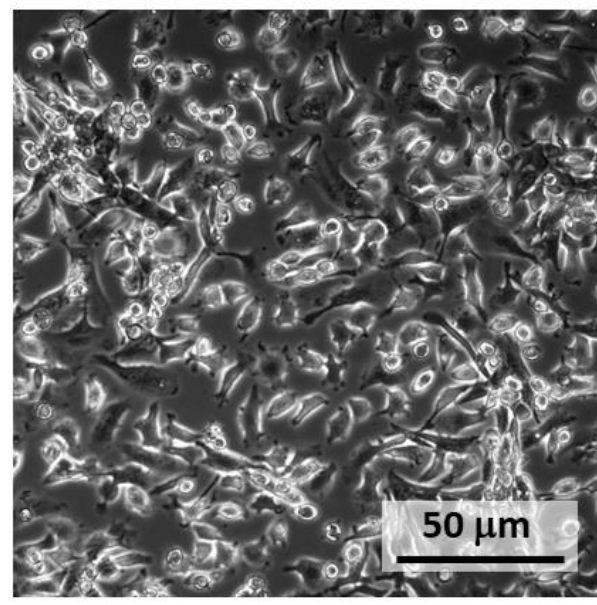

(b)

Figure A1. Representative images of the primary mouse (a) and rat (b) airway cell culture images 7 $\mathrm{d}$ after plating before the treatment with poly (I:C) and exosome collection. The cells on the bottom are fibroblasts, and the small cells organised in colonies on top of the fibroblasts are epithelial cells.

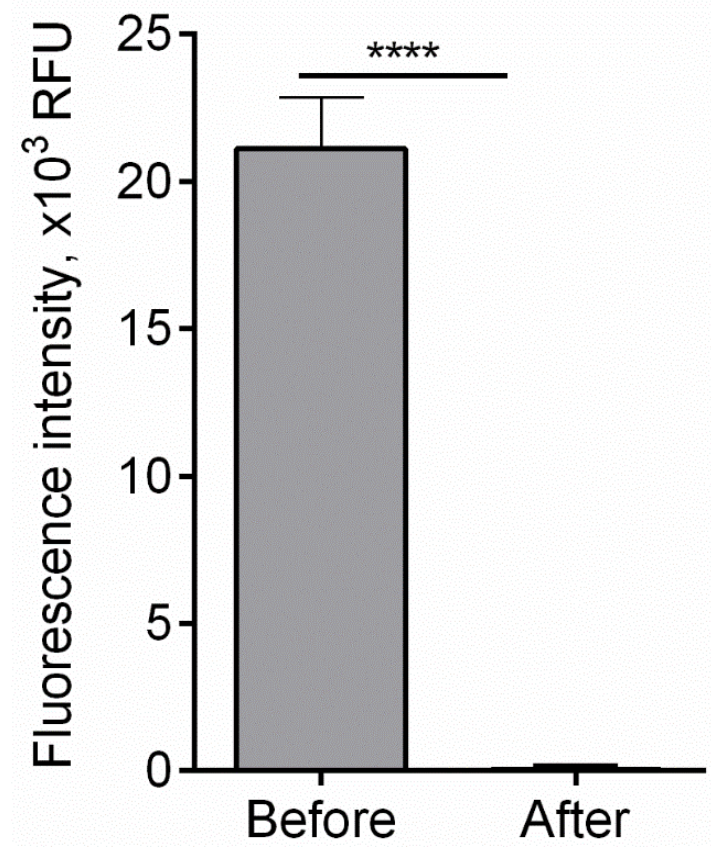

Figure A2. AF555-RNR retention by Exo-Spin collumns efficiency. The sample fluorescence data are presented as averages of 3 esperiments of 2 technical replicates; ${ }^{* * *}$ means statistically significant difference when $p<0.0001$. 

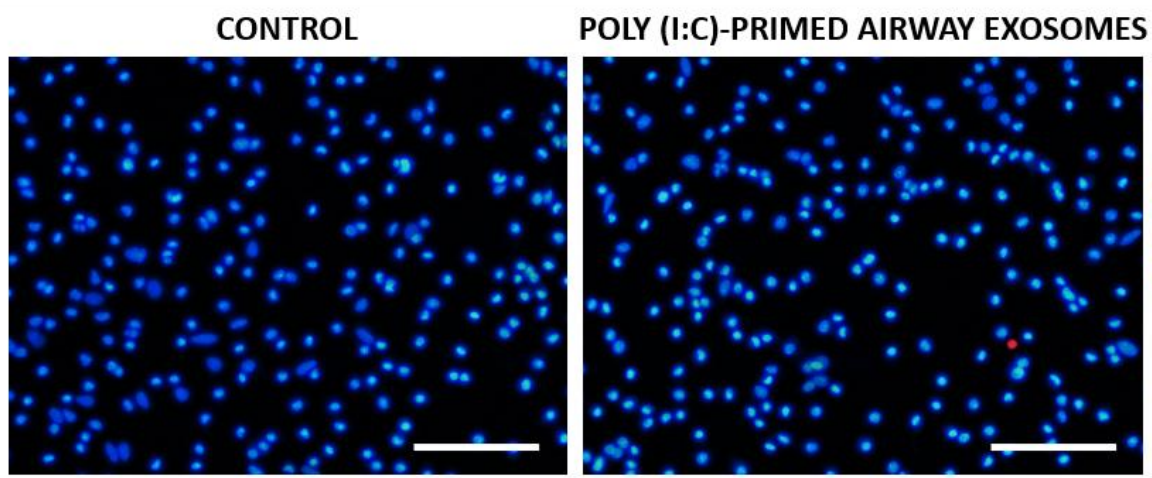

\section{UNTREATED AIRWAY EXOSOMES}

Figure A3. Representative images of viability evaluation of airway exosome-treated microglial cultures. The cells were stained with Hoechst33342 to visualise all nuclei blue and with propidium iodide to detect dying cells with lost plasma membrane integrity (red fluorescence of the nuclei).

\section{References}

1. Goody, M.F.; Sullivan, C.; Kim, C.H. Studying the immune response to human viral infections using zebrafish. Dev. Comp. Immunol. 2014, 46, 84-95. [CrossRef]

2. Mackie, P.L. The classification of viruses infecting the respiratory tract. Paediatr. Respir. Rev. 2003, 4, 84-90. [CrossRef]

3. Chahar, H.S.; Corsello, T.; Kudlicki, A.S.; Komaravelli, N.; Casola, A. Respiratory Syncytial Virus Infection Changes Cargo Composition of Exosome Released from Airway Epithelial Cells. Sci. Rep. 2018, 8, 387. [CrossRef] [PubMed]

4. Hassanpour, M.; Rezaie, J.; Nouri, M.; Panahi, Y. The role of extracellular vesicles in COVID-19 virus infection. Infect. Genet. Evol. 2020, 85, 104422. [CrossRef]

5. Gunasekaran, M.; Bansal, S.; Ravichandran, R.; Sharma, M.; Perincheri, S.; Rodriguez, F.; Hachem, R.; Fisher, C.E.; Limaye, A.P.; Omar, A.; et al. Respiratory viral infection in lung transplantation induces exosomes that trigger chronic rejection. J. Heart Lung Transplant. 2020, 39, 379-388. [CrossRef] [PubMed]

6. Banks, W.A.; Sharma, P.; Bullock, K.M.; Hansen, K.M.; Ludwig, N.; Whiteside, T.L. Transport of extracellular vesicles across the blood-brain barrier: Brain pharmacokinetics and effects of inflammation. Int. J. Mol. Sci. 2020, 21, 4407. [CrossRef] [PubMed]

7. Alvarez-Erviti, L.; Seow, Y.; Yin, H.; Betts, C.; Lakhal, S.; Wood, M.J.A. Delivery of siRNA to the mouse brain by systemic injection of targeted exosomes. Nat. Biotechnol. 2011, 29, 341-345. [CrossRef] [PubMed]

8. Saint-Pol, J.; Gosselet, F.; Duban-Deweer, S.; Pottiez, G.; Karamanos, Y. Targeting and Crossing the Blood-Brain Barrier with Extracellular Vesicles. Cells 2020, 9, 851. [CrossRef] [PubMed]

9. Zomer, A.; Vendrig, T.; Hopmans, E.S.; van Eijndhoven, M.; Middeldorp, J.M.; Pegtel, D.M. Exosomes: Fit to deliver small RNA. Commun. Integr. Biol. 2010, 3, 447. [CrossRef] [PubMed]

10. Zhang, Y.; Liu, Y.; Liu, H.; Tang, W.H. Exosomes: Biogenesis, Biologic Function and Clinical Potential; BioMed Central Ltd.: London, UK, 2019; Volume 9.

11. Keerthikumar, S.; Chisanga, D.; Ariyaratne, D.; Al Saffar, H.; Anand, S.; Zhao, K.; Samuel, M.; Pathan, M.; Jois, M.; Chilamkurti, N.; et al. ExoCarta: A Web-Based Compendium of Exosomal Cargo. J. Mol. Biol. 2016, 428, 688-692. [CrossRef]

12. Rajagopal, C.; Harikumar, K.B. The origin and functions of exosomes in cancer. Front. Oncol. 2018, 8, 66. [CrossRef]

13. Xu, M.Y.; Ye, Z.S.; Song, X.T.; Huang, R.C. Differences in the cargos and functions of exosomes derived from six cardiac cell types: A systematic review. Stem Cell Res. Ther. 2019, 10, 194. [CrossRef]

14. Flanagan, J.; Middeldorp, J.; Sculley, T. Localization of the Epstein-Barr virus protein LMP 1 to exosomes. J. Gen. Virol. 2003, 84, 1871-1879. [CrossRef]

15. Narayanan, A.; Iordanskiy, S.; Das, R.; Van Duyne, R.; Santos, S.; Jaworski, E.; Guendel, I.; Sampey, G.; Dalby, E.; Iglesias-Ussel, M.; et al. Exosomes derived from HIV-1-infected cells contain trans-activation response element RNA. J. Biol. Chem. 2013, 288, 20014-20033. [CrossRef]

16. Choi, H.; Lee, H.; Kim, S.R.; Gho, Y.S.; Lee, S.K. Epstein-Barr Virus-Encoded MicroRNA BART15-3p Promotes Cell Apoptosis Partially by Targeting BRUCE. J. Virol. 2013, 87, 8135-8144. [CrossRef] [PubMed]

17. Pegtel, D.M.; Cosmopoulos, K.; Thorley-Lawson, D.A.; Van Eijndhoven, M.A.J.; Hopmans, E.S.; Lindenberg, J.L.; De Gruijl, T.D.; Würdinger, T.; Middeldorp, J.M. Functional delivery of viral miRNAs via exosomes. Proc. Natl. Acad. Sci. USA 2010, 107, 6328-6333. [CrossRef]

18. Haneklaus, M.; Gerlic, M.; Kurowska-Stolarska, M.; Rainey, A.-A.; Pich, D.; McInnes, I.B.; Hammerschmidt, W.; O’Neill, L.A.J.; Masters, S.L. Cutting Edge: miR-223 and EBV miR-BART15 Regulate the NLRP3 Inflammasome and IL-1 $\beta$ Production. J. Immunol. 2012, 189, 3795-3799. [CrossRef]

19. Li, Q.; Barres, B.A. Microglia and macrophages in brain homeostasis and disease. Nat. Rev. Immunol. 2018, 18, 225-242. [CrossRef] [PubMed]

20. Aguzzi, A.; Barres, B.A.; Bennett, M.L. Microglia: Scapegoat, saboteur, or something else? Science 2013, 339, 156-161. [CrossRef] 
21. Paolicelli, R.C.; Bolasco, G.; Pagani, F.; Maggi, L.; Scianni, M.; Panzanelli, P.; Giustetto, M.; Ferreira, T.A.; Guiducci, E.; Dumas, L.; et al. Synaptic pruning by microglia is necessary for normal brain development. Science 2011, 333, 1456-1458. [CrossRef] [PubMed]

22. Fu, R.; Shen, Q.; Xu, P.; Luo, J.J.; Tang, Y. Phagocytosis of microglia in the central nervous system diseases. Mol. Neurobiol. 2014, 49, 1422-1434. [CrossRef]

23. Brown, G.C.; Neher, J.J. Microglial phagocytosis of live neurons. Nat. Rev. Neurosci. 2014, 15, 209-216. [CrossRef] [PubMed]

24. Ransohoff, R.M. How neuroinflammation contributes to neurodegeneration. Science 2016, 353, 777-783. [CrossRef]

25. Wendeln, A.-C.; Degenhardt, K.; Kaurani, L.; Gertig, M.; Ulas, T.; Jain, G.; Wagner, J.; Häsler, L.M.; Wild, K.; Skodras, A.; et al. Innate immune memory in the brain shapes neurological disease hallmarks. Nature 2018, 556, 332-338. [CrossRef] [PubMed]

26. Weinberg, S.E.; Sena, L.A.; Chandel, N.S. Mitochondria in the Regulation of Innate and Adaptive Immunity. Immunity 2015, 42, 406-417. [CrossRef] [PubMed]

27. Balion, Z.; Cèpla, V.; Svirskiene, N.; Svirskis, G.; Druceikaitè, K.; Inokaitis, H.; Rusteikaitè, J.; Masilionis, I.; Stankevičienè, G.; Jelinskas, T.; et al. Cerebellar cells self-assemble into functional organoids on synthetic, chemically crosslinked ECM-mimicking peptide hydrogels. Biomolecules 2020, 10, 754. [CrossRef] [PubMed]

28. Dematteis, G.; Vydmantaitè, G.; Ruffinatti, F.A.; Chahin, M.; Farruggio, S.; Barberis, E.; Ferrari, E.; Marengo, E.; Distasi, C.; Morkūnienè, R.; et al. Proteomic analysis links alterations of bioenergetics, mitochondria-ER interactions and proteostasis in hippocampal astrocytes from 3xTg-AD mice. Cell Death Dis. 2020, 11, 645. [CrossRef]

29. West, A.P.; Shadel, G.S.; Ghosh, S. Mitochondria in innate immune responses. Nat. Rev. Immunol. 2011, 11, 389-402. [CrossRef]

30. Kim, H.J.; Kim, C.H.; Ryu, J.H.; Kim, M.J.; Park, C.Y.; Lee, J.M.; Holtzman, M.J.; Yoon, J.H. Reactive oxygen species induce antiviral innate immune response through IFN- $\lambda$ regulation in human nasal epithelial cells. Am. J. Respir. Cell Mol. Biol. 2013, 49, 855-865. [CrossRef]

31. Kim, S.; Kim, M.J.; Park, D.Y.; Chung, H.J.; Kim, C.H.; Yoon, J.H.; Kim, H.J. Mitochondrial reactive oxygen species modulate innate immune response to influenza A virus in human nasal epithelium. Antivir. Res. 2015, 119, 78-83. [CrossRef]

32. Carvajal, L.A.; Pérez, C.P. Epidemiology of Respiratory Infections. Pediatr. Respir. Dis. 1976, 263. [CrossRef]

33. Eugenia, M.; Patricia, D.; Horacio, L.; Ocadiz-Delgado, R.; Cabello-Gutierrez, C. Pathogenesis of Viral Respiratory Infection. In Respiratory Disease and Infection-A New Insight; InTech: London, UK, 2013.

34. Steel, A.J.; Eslick, G.D. Herpes viruses increase the risk of Alzheimer's disease: A meta-analysis. J. Alzheimer's Dis. 2015, 47, 351-364. [CrossRef]

35. Klein, R.S.; Garber, C.; Funk, K.E.; Salimi, H.; Soung, A.; Kanmogne, M.; Manivasagam, S.; Agner, S.; Cain, M. Neuroinflammation During RNA Viral Infections. Annu. Rev. Immunol. 2019, 37, 73-95. [CrossRef] [PubMed]

36. Amruta, N.; Chastain, W.H.; Paz, M.; Solch, R.J.; Murray-Brown, I.C.; Befeler, J.B.; Gressett, T.E.; Longo, M.T.; Engler-Chiurazzi, E.B.; Bix, G. SARS-CoV-2 mediated neuroinflammation and the impact of COVID-19 in neurological disorders. Cytokine Growth Factor Rev. 2021, 58, 1-15. [CrossRef]

37. Schorey, J.S.; Cheng, Y.; Singh, P.P.; Smith, V.L. Exosomes and other extracellular vesicles in host-pathogen interactions. EMBO Rep. 2015, 16, 24-43. [CrossRef]

38. Quah, B.J.C.; O’Neill, H.C. Mycoplasma contaminants present in exosome preparations induce polyclonal B cell responses. J. Leukoc. Biol. 2007, 82, 1070-1082. [CrossRef]

39. Bhatnagar, S.; Schorey, J.S. Exosomes released from infected macrophages contain Mycobacterium avium glycopeptidolipids and are proinflammatory. J. Biol. Chem. 2007, 282, 25779-25789. [CrossRef] [PubMed]

40. Kulkarni, R.; Prasad, A. Exosomes Derived from HIV-1 Infected DCs Mediate Viral trans-Infection via Fibronectin and Galectin-3. Sci. Rep. 2017, 7, 14787. [CrossRef]

41. Bello-Morales, R.; Praena, B.; de la Nuez, C.; Rejas, M.T.; Guerra, M.; Galán-Ganga, M.; Izquierdo, M.; Calvo, V.; Krummenacher, C.; López-Guerrero, J.A. Role of Microvesicles in the Spread of Herpes Simplex Virus 1 in Oligodendrocytic Cells. J. Virol. 2018, 92, 88-106. [CrossRef] [PubMed]

42. Lenassi, M.; Cagney, G.; Liao, M.; Vaupotič, T.; Bartholomeeusen, K.; Cheng, Y.; Krogan, N.J.; Plemenitaš, A.; Peterlin, B.M. HIV Nef is secreted in exosomes and triggers apoptosis in bystander CD4 ${ }^{+} \mathrm{T}$ cells. Traffic 2010, 11, 110-122. [CrossRef]

43. Longatti, A. The dual role of exosomes in hepatitis A and C virus transmission and viral immune activation. Viruses 2015, 7, 6707-6715. [CrossRef] [PubMed]

44. Gourévitch, B.; Kay, L.M.; Martin, C. Directional coupling from the olfactory bulb to the hippocampus during a go/no-go odor discrimination task. J. Neurophysiol. 2010, 103, 2633-2641. [CrossRef] [PubMed]

45. Natale, G.; Limanaqi, F.; Busceti, C.L.; Mastroiacovo, F.; Nicoletti, F.; Puglisi-Allegra, S.; Fornai, F. Glymphatic System as a Gateway to Connect Neurodegeneration from Periphery to CNS. Front. Neurosci. 2021, 15, 92. [CrossRef] [PubMed]

46. Li, J.J.; Wang, B.; Kodali, M.C.; Chen, C.; Kim, E.; Patters, B.J.; Lan, L.; Kumar, S.; Wang, X.; Yue, J.; et al. In vivo evidence for the contribution of peripheral circulating inflammatory exosomes to neuroinflammation. J. Neuroinflamm. 2018, 15, 1-16. [CrossRef] [PubMed]

47. Zhuang, X.; Xiang, X.; Grizzle, W.; Sun, D.; Zhang, S.; Axtell, R.C.; Ju, S.; Mu, J.; Zhang, L.; Steinman, L.; et al. Treatment of Brain Inflammatory Diseases by Delivering Exosome Encapsulated Anti-inflammatory Drugs From the Nasal Region to the Brain. Mol. Ther. 2011, 19, 1769-1779. [CrossRef] 
48. Chen, C.C.; Liu, L.; Ma, F.; Wong, C.W.; Guo, X.E.; Chacko, J.V.; Farhoodi, H.P.; Zhang, S.X.; Zimak, J.; Ségaliny, A.; et al. Elucidation of Exosome Migration Across the Blood-Brain Barrier Model In Vitro. Cell. Mol. Bioeng. 2016, 9, 509-529. [CrossRef]

49. Liangsupree, T.; Multia, E.; Riekkola, M.L. Modern isolation and separation techniques for extracellular vesicles. J. Chromatogr. A 2021, 1636, 461773. [CrossRef]

50. Li, P.; Kaslan, M.; Lee, S.H.; Yao, J.; Gao, Z. Progress in Exosome Isolation Techniques. Theranostics 2017, 7, 789. [CrossRef]

51. Ayala-Mar, S.; Donoso-Quezada, J.; Gallo-Villanueva, R.C.; Perez-Gonzalez, V.H.; González-Valdez, J. Recent advances and challenges in the recovery and purification of cellular exosomes. Electrophoresis 2019, 40, 3036. [CrossRef]

52. Brennan, K.; Martin, K.; FitzGerald, S.P.; O'Sullivan, J.; Wu, Y.; Blanco, A.; Richardson, C.; Mc Gee, M.M. A comparison of methods for the isolation and separation of extracellular vesicles from protein and lipid particles in human serum. Sci. Rep. 2020, 10, 1039. [CrossRef]

53. Patel, G.K.; Khan, M.A.; Zubair, H.; Srivastava, S.K.; Khushman, M.; Singh, S.; Singh, A.P. Comparative analysis of exosome isolation methods using culture supernatant for optimum yield, purity and downstream applications. Sci. Rep. 2019, 9, 5335. [CrossRef] [PubMed]

54. Crescitelli, R.; Lässer, C.; Szabó, T.G.; Kittel, A.; Eldh, M.; Dianzani, I.; Buzás, E.I.; Lötvall, J. Distinct RNA profiles in subpopulations of extracellular vesicles: Apoptotic bodies, microvesicles and exosomes. J. Extracell. Vesicles 2013, 2, 20677. [CrossRef]

55. Tauro, B.J.; Greening, D.W.; Mathias, R.A.; Mathivanan, S.; Ji, H.; Simpson, R.J. Two distinct populations of exosomes are released from LIM1863 colon carcinoma cell-derived organoids. Mol. Cell. Proteom. 2013, 12, 587-598. [CrossRef] [PubMed]

56. Dikalov, S.I.; Harrison, D.G. Methods for detection of mitochondrial and cellular reactive oxygen species. Antioxid. Redox Signal. 2014, 20, 372-382. [CrossRef]

57. Bulua, A.C.; Simon, A.; Maddipati, R.; Pelletier, M.; Park, H.; Kim, K.Y.; Sack, M.N.; Kastner, D.L.; Siegel, R.M. Mitochondrial reactive oxygen species promote production of proinflammatory cytokines and are elevated in TNFR1-associated periodic syndrome (TRAPS). J. Exp. Med. 2011, 208, 519-533. [CrossRef]

58. Chen, Y.; Zhou, Z.; Min, W. Mitochondria, oxidative stress and innate immunity. Front. Physiol. 2018, 9, 1487. [CrossRef]

59. Subramanian, N.; Natarajan, K.; Clatworthy, M.R.; Wang, Z.; Germain, R.N. The adaptor MAVS promotes NLRP3 mitochondrial localisation and inflammasome activation. Cell 2013, 153, 348-361. [CrossRef] [PubMed]

60. Onomoto, K.; Onoguchi, K.; Yoneyama, M. Regulation of RIG-I-like receptor-mediated signaling: Interaction between host and viral factors. Cell. Mol. Immunol. 2021, 18, 539-555. [CrossRef]

61. Heneka, M.T.; Kummer, M.P.; Stutz, A.; Delekate, A.; Schwartz, S.; Vieira-Saecker, A.; Griep, A.; Axt, D.; Remus, A.; Tzeng, T.C.; et al. NLRP3 is activated in Alzheimer's disease and contributes to pathology in APP/PS1 mice. Nature 2013, 493, 674-678 [CrossRef] [PubMed]

62. Lee, E.; Hwang, I.; Park, S.; Hong, S.; Hwang, B.; Cho, Y.; Son, J.; Yu, J.W. MPTP-driven NLRP3 inflammasome activation in microglia plays a central role in dopaminergic neurodegeneration. Cell Death Differ. 2019, 26, 213-228. [CrossRef]

63. Liu, T.; Zhang, L.; Joo, D.; Sun, S.-C. NF-kB signaling in inflammation. Signal Transduct. Target. Ther. 2017, 2, 17023. [CrossRef] [PubMed]

64. Yang, C.H.; Murti, A.; Pfeffer, S.R.; Basu, L.; Kim, J.G.; Pfeffer, L.M. IFN $\alpha$ / $\beta$ promotes cell survival by activating NF-kB. Proc. Natl. Acad. Sci. USA 2000, 97, 13631-13636. [CrossRef] [PubMed]

65. Uematsu, S.; Akira, S. Toll-like Receptors and Type I Interferons*. J. Biol. Chem. 2007, 282, 15319-15323. [CrossRef]

66. Negishi, H.; Osawa, T.; Ogami, K.; Ouyang, X.; Sakaguchi, S.; Koshiba, R.; Yanai, H.; Seko, Y.; Shitara, H.; Bishop, K.; et al. A critical link between Toll-like receptor 3 and type II interferon signaling pathways in antiviral innate immunity. Proc. Natl. Acad. Sci. USA 2008, 105, 20446-20451. [CrossRef]

67. Frank-Bertoncelj, M.; Pisetsky, D.S.; Kolling, C.; Michel, B.A.; Gay, R.E.; Jüngel, A.; Gay, S. TLR3 Ligand Poly(I:C) Exerts Distinct Actions in Synovial Fibroblasts When Delivered by Extracellular Vesicles. Front. Immunol. 2018, 9, 29. [CrossRef] [PubMed]

68. Steer, S.A.; Corbett, J.A. The role and regulation of COX-2 during viral infection. Viral Immunol. 2003, 16, 447-460. [CrossRef]

69. Sil, S.; Ghosh, T. Role of cox-2 mediated neuroinflammation on the neurodegeneration and cognitive impairments in colchicine induced rat model of Alzheimer's Disease. J. Neuroimmunol. 2016, 291, 115-124. [CrossRef]

70. Teismann, P.; Tieu, K.; Choi, D.-K.; Wu, D.-C.; Naini, A.; Hunot, S.; Vila, M.; Jackson-Lewis, V.; Przedborski, S. Cyclooxygenase-2 is instrumental in Parkinson's disease neurodegeneration. Proc. Natl. Acad. Sci. USA 2003, 100, 5473-5478. [CrossRef] 